\title{
WestVirginiaUniversity
}

THE RESEARCH REPOSITORY @ WVU

Graduate Theses, Dissertations, and Problem Reports

2017

\section{Scholars and knowledge sharing on twitter}

Pravija Krishna

Follow this and additional works at: https://researchrepository.wvu.edu/etd

\section{Recommended Citation}

Krishna, Pravija, "Scholars and knowledge sharing on twitter" (2017). Graduate Theses, Dissertations, and Problem Reports. 4006.

https://researchrepository.wvu.edu/etd/4006

This Problem/Project Report is protected by copyright and/or related rights. It has been brought to you by the The Research Repository @WVU with permission from the rights-holder(s). You are free to use this Problem/Project Report in any way that is permitted by the copyright and related rights legislation that applies to your use. For other uses you must obtain permission from the rights-holder(s) directly, unless additional rights are indicated by a Creative Commons license in the record and/ or on the work itself. This Problem/Project Report has been accepted for inclusion in WVU Graduate Theses, Dissertations, and Problem Reports collection by an authorized administrator of The Research Repository @ WVU. For more information, please contact researchrepository@mail.wvu.edu. 


\title{
Scholars and Knowledge Sharing on Twitter
}

\author{
Pravija Krishna \\ Problem Report submitted \\ to the College of Engineering and Mineral Resources \\ at West Virginia University \\ in partial fulfillment of the requirements for the degree of \\ Master of Science in \\ Computer Science
}
Dr. Saiph Savage, Chair
Dr. Elaine M. Eschen
Dr. Donald Adjeroh

Lane Department of Computer Science and Electrical Engineering

Morgantown, West Virginia

2017

Keywords: [Twitter, Likes, Retweets, Twitter bot, Scholar, Novice, REST API, Tweepy, Twitter API, Sharing]

(C) 2017 Pravija Krishna 


\title{
ABSTRACT
}

\section{Scholars and Knowledge Sharing on Twitter}

\author{
Pravija Krishna
}

There has always been an invisible gap between members of the scientific community - scholars (professors $\&$ researchers), science fans (subject matter experts) and novices (general public who are enthusiastic about science or any other field). This report aims at bridging that gap and exploring to what extent the scientific community is willing and able to share their knowledge with the general public. Several studies were conducted both on Twitter and manually. The results of these studies were vital in proposing a system that could help increase the level of sharing of knowledge by scholars and science fans in addition to motivating novices to explore the research areas of their favorite fields. The proposed system was implemented on Twitter. This report documents all the findings of the studies conducted, the proposed system and process flow. The later part of the report documents how the system was implemented on Twitter. This report is concluded by discussing the results that show how scholars and science fans and novices reacted to the system and limitations of the system. 


\section{TABLE OF CONTENTS}

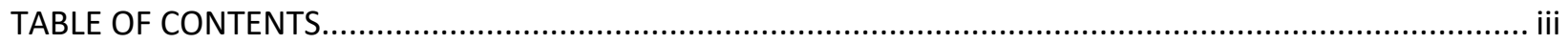

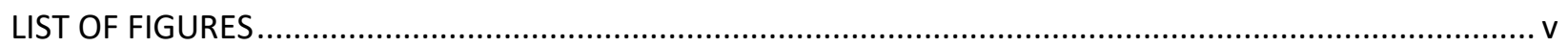

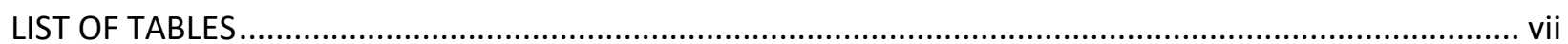

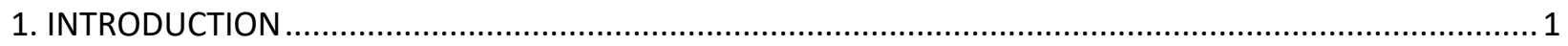

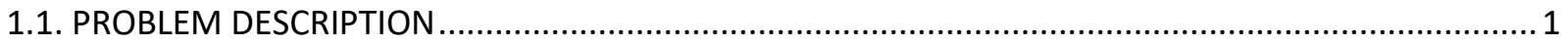

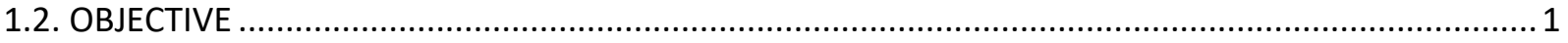

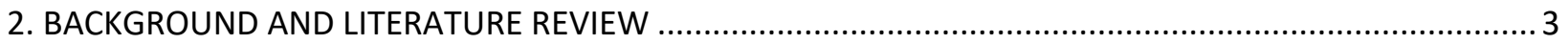

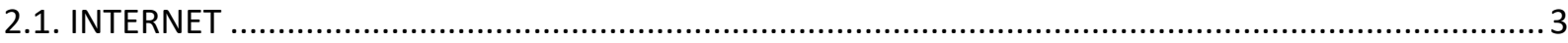

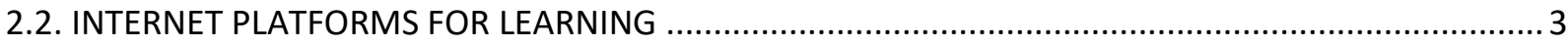

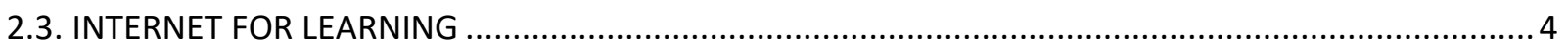

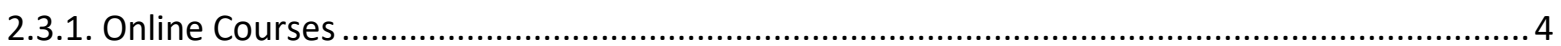

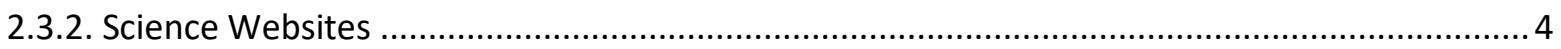

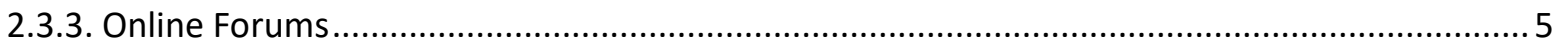

2.4. TWITTER

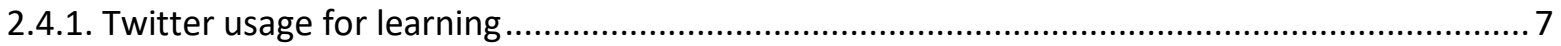

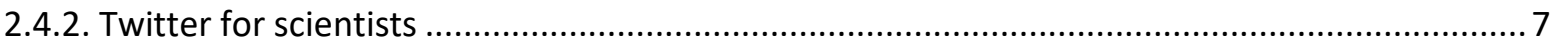

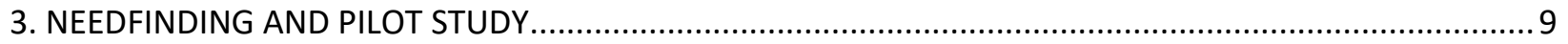

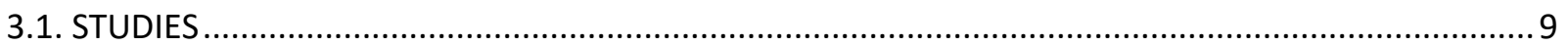

3.1.1. Study I- Collection of Twitter Usernames of Scholars and Science Fans ................................ 9

3.1.2. Study II- Scholars \& Science fans are requested to share short snippets of research work via

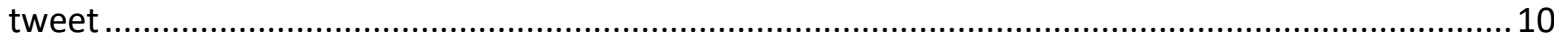

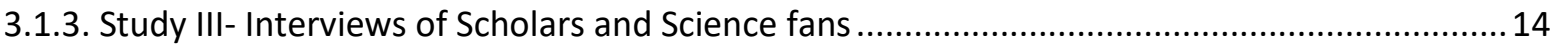

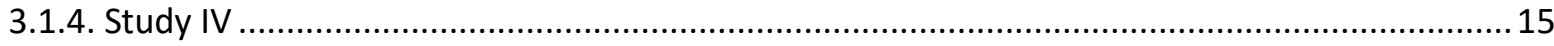

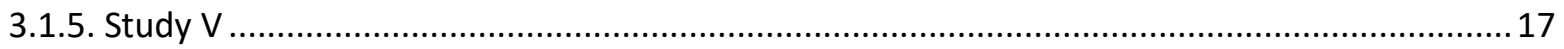

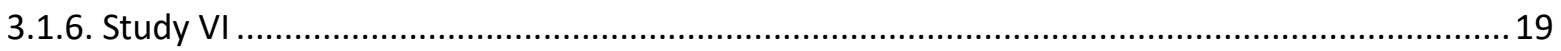

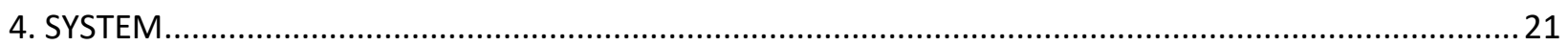

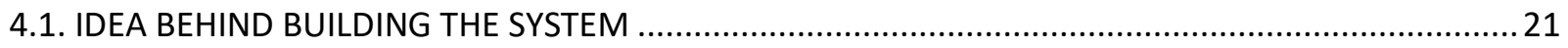

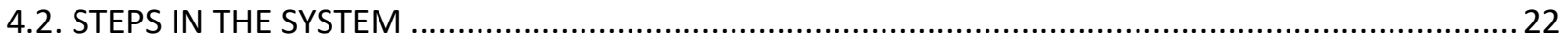

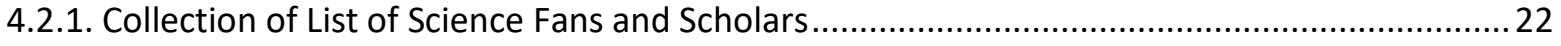

4.2.2. Requesting Short Summary of Favorite Research Paper .....................................................22

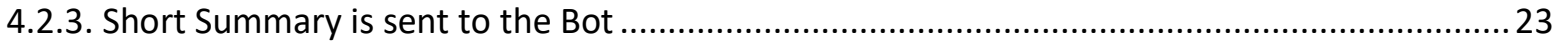

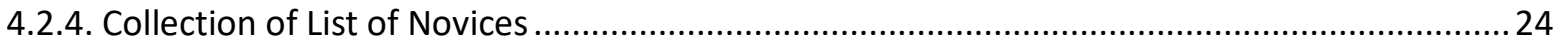


4.2.5. Send Short Summary of a Research Paper to Novices........................................................ 24

4.2.6. Request Novices to Retweet Science Fan and Bot............................................................... 25

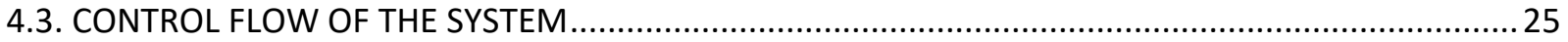

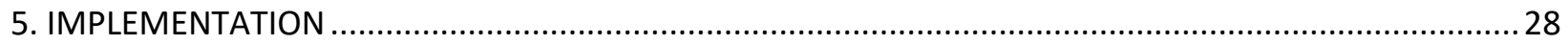

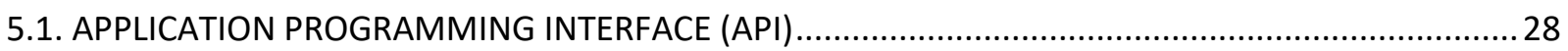

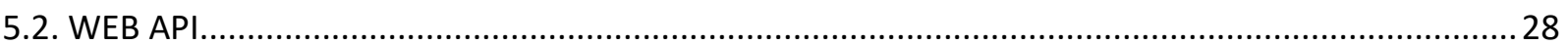

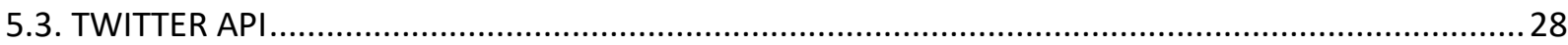

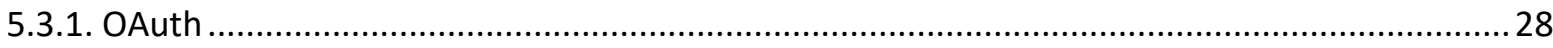

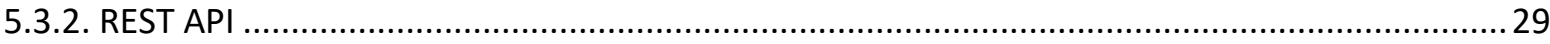

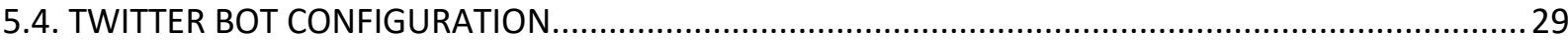

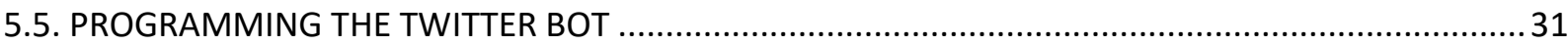

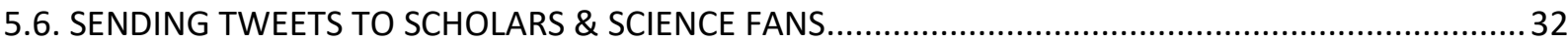

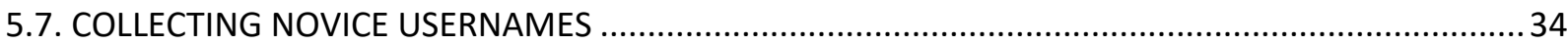

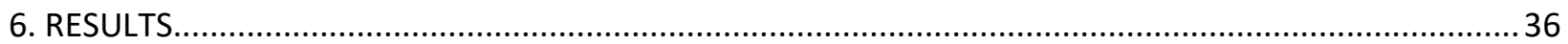

6.1. SCHOLARS \& SCIENCE FANS RESPONSES TO THE BOT AND OTHER STATISTICS............................36

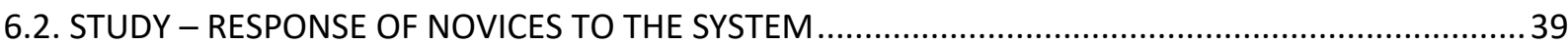

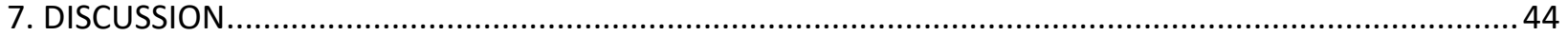

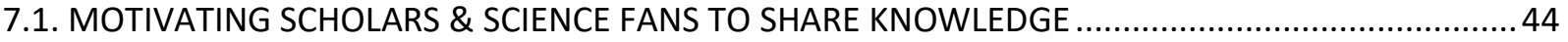

7.2. MOTIVATING NOVICES TO CHECK OUT RESEARCH ARTICLES.................................................. 44

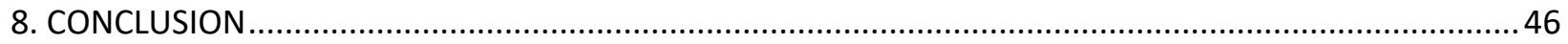

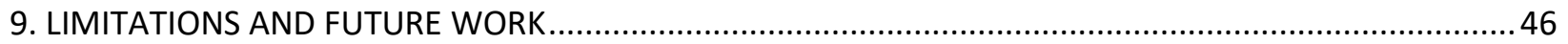

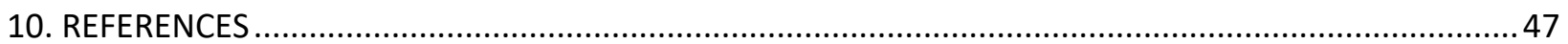

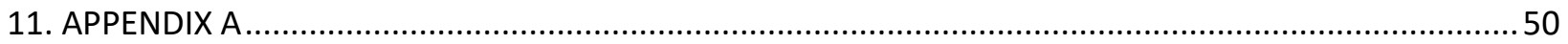

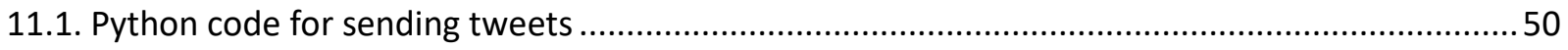

11.2. Python code for collecting usernames into csv file based on required keyword .........................51 


\section{LIST OF FIGURES}

Figure 4-1 Figure showing the collection of Twitter usernames of Scholars \& Science fans ........ 9

Figure 4-2 FIgure illustrating how Scholars \& Science fans are requested to share short snippets of research work via tweet..... 10

Figure 4-3 Bot Profile on Twitter .11

Figure 4-4 Tweets sent manually to Scholars \& science fans 12

Figure 4-5 Tweet with Image attachment and its response 13

Figure 4-6 Statistics of Tweets to scientists and responses received 13

Figure 4-7 Figure illustrating the interviews of scholars and science fans .14

Figure 4-8 Statistics of the scientists sharing on social media...... .15

Figure 4-9 Figure illustrating the interviews conducted on graduate students 16

Figure 4-10 Statistics of graduate students' usage of social media for learning 16

Figure 4-11 Figure illustrating the interviews conducted on undergrad students 17

Figure 4-12 Statistics of Undergraduate students' usage of social media for learning........... 18

Figure 4-13 Statistics of Undergraduate students' usage of Twitter for learning 19

Figure 4-14 Figure illustrating Pilot study 20

Figure 4-15 Pilot Study .20

Figure 5-1 Collection of List of Science Fans and Scholars .22

Figure 5-2 Requesting Short Summary of Favorite Research Paper .23

Figure 5-3 Short Summary is sent to the Bot. .23

Figure 5-4 Collection of List of Novices .24

Figure 5-5 Send Short Summary of a Research Paper to Novices. .24

Figure 5-6 Request Novices to Retweet Science Fan and Bot .25

Figure 5-7 Control Flow of the System .27

Figure 6-1 Bot account on Twitter. .29

Figure 6-2 Creating Twitter Application .30 
Figure 6-3 Access Tokens for the Twitter application

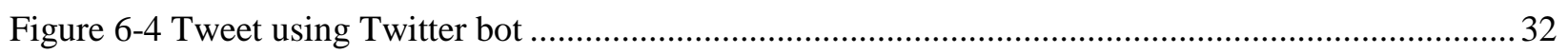

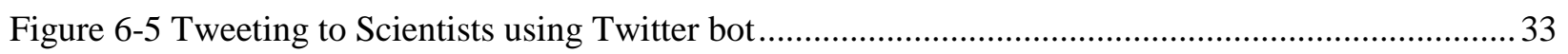

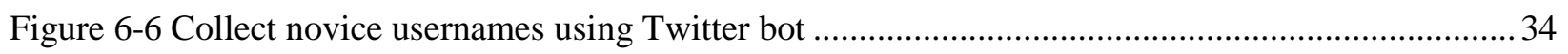

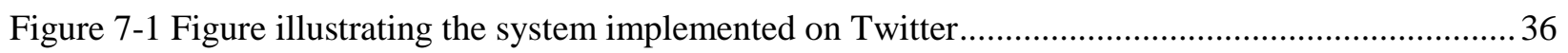

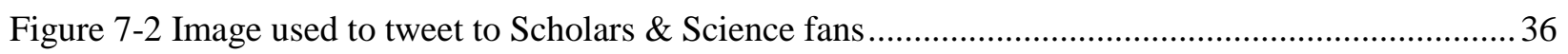

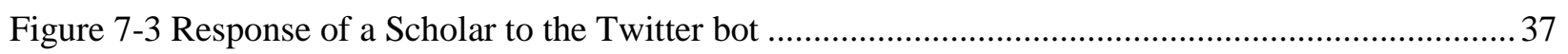

Figure 7-4 Twitter Bot profile after implementing the system .......................................................... 38

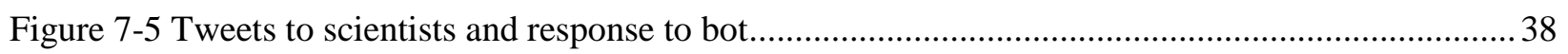

Figure 7-6 Figure illustrating simulation of system to novices and collection on responses...................... 39

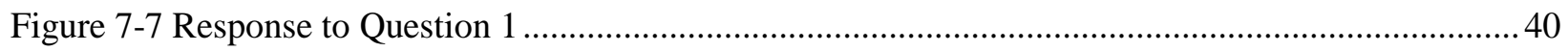

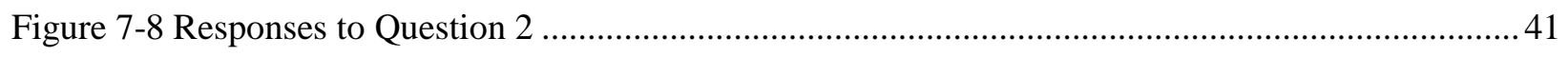

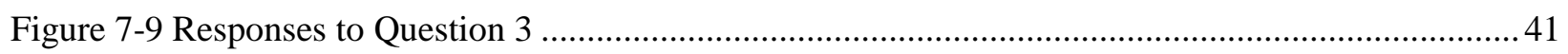

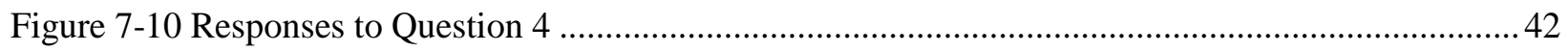

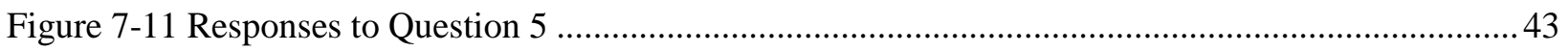




\section{LIST OF TABLES}

Table 1 Science websites and number of visitors. ............................................................................... 4

Table 2 Social Networking websites and number of visitors.............................................................. 5 


\section{INTRODUCTION}

\subsection{PROBLEM DESCRIPTION}

Many people with different backgrounds often explore and learn science through informal sources out of their own interest [1]. Sometimes, people with a passionate inclination towards science are far from being updated with the latest research breakthroughs or they are sometimes even miscommunicated [2]. This makes people who are not scientists in a field lack science literacy[3]. Sometimes even scientists themselves do not understand research articles that are outside of their area of expertise [4]. There are two main reasons behind this. According to Hyman Levy [5], the problem with science and scientific explanation is that it tends to be incomprehensible to anyone except the expert of it. Anyone who does not understand the literature are perceived to be stupid [2]. A layman thinks of science as a kind of vault to which only a scientist knows the combination. In this safe, he presumes that there are smaller ones labelled as Physics, Chemistry, Biology, Geology, Astronomy etc. [2]. Secondly, in spite of the availability of several websites and other sources, where a toned-down version of the contemporary research descriptions is available, they have less visitors compared to the entertainment websites. Research has been done which talks about how scientists collaborating with the common people is beneficial in bridging the gap between people who are interested in science and the scientists [6]. We can reach out and motivate more people who are willing to collaborate if there was a way that people who are genuinely interested and curious about a field can be directly sent information regarding current research in that field. This directed approach used in social media has proven to be useful in the field of marketing as an effective communication tool [7]. Its benefits can be derived if used for the purpose of spreading scientific research knowledge.

\subsection{OBJECTIVE}

Social networking sites, especially Twitter, are being used by professors [8] and students [9] to search for information and learning. According to the research done by Hiller A. Spires [9]., students like to use the internet to do research and find information. Though there are many websites that carry out scientific discussions, share scientific information etc. like forums, they have much less visibility than Twitter. Twitter already has around 300 million users of which $40 \%$ are people who work in technological fields and the website is accessed over a billion times each month [10]. This makes it a perfect platform to extend it to educational purposes. This report shows how we can use the existing platform of Twitter to build a system where scholars and scientists share information with the public. The results of the implementation of the system are also shown. Scholars and Scientists are made to share short summaries or snippets of information about their research or their favorite research papers. This allows users to get exposure to new 
research and motivate them to explore more research articles of their field of interest. Generally, these short summaries are written in easily understandable language, which allows naïve users to read and get acquainted with the research that is going on. Hence it results in extending the reach of research papers and their visibility beyond just the scientific community and also helps in motivating people enthusiastic about science into research. 


\section{BACKGROUND AND LITERATURE REVIEW}

\subsection{INTERNET}

In the past, knowledge sharing happened amongst family and a community [11]. Currently it evolved into educational institutions, vast libraries and interaction with peers via available technology [11]. Right from the beginning, there was a concept of Learning on Demand [12] in education or work. In the present-day learning on demand can be done by the click of a button using internet. The internet today holds massive amounts of information and resources. In the pre-internet period, doing research either for academic or personal purposes, involved many hours spent in the library referencing innumerable amount of printed material. It was very tedious and time consuming to search for relevant sources and related research work. Even communicating with peers about research was time consuming and hence was limited. But today, doing research and searching for required information has been revolutionized. Libraries holding countless books and articles turned into electronic databases. These databases are accessible by a mouse click from anywhere in the world thus breaking all geographical walls and cutting short the time spent in physically searching at a library.

\subsection{INTERNET PLATFORMS FOR LEARNING}

In the recent times, communication and interaction has acquired a greater importance than individual learning [13]. Learning networks allow people to share their views with others and to share information with each other [11]. Anyone who wants to learn about anything can look at various types of online sources like websites, forums, mailing lists, blogs, e-learning courses etc. Discussing with peers has become quick and easy with forums. They are a kind of message boards where anyone can post questions to which others respond. This forms a message thread and gives a platform for discussions. Blogs also allow users to gain specific knowledge but in a more informal way. Blogs are small websites that have discussions or share information about different topics. Other ways by which people can share and access information quickly are by means of social networking sites.

Social networking sites like Twitter allow microblogging which is like blogging but with a limitation on the size of the post. These social networking sites are one of the best resources available for quick interaction and quick learning through instant messaging and microblogging. The current day education demands students to be capable of self-learning. Studies show that most students turn to internet more than referring a book, if they are looking for information [9]. 


\subsection{INTERNET FOR LEARNING}

\subsubsection{Online Courses}

Ever since internet came into existence, it slowly rose to find its way into every field, be it Commerce, Medicine, Finance or Education. It not only holds vast amount of information for people to access, but also has platforms to promote, share and exchange information. Specifically, in the education field, universities started using internet to give distant learning programs online [14], [15]. It was used by institutions to merely replace sending documents via post office to transferring files and course documents via e-mail [14]; thus, replacing correspondence (distant education) courses to online courses. They became popular because it gave the learners convenience of time and length of the study [16]. By early 2000s more than a million students started taking the online courses because of the flexibility and convenience and the number of enrollments increased over time [15]. Digital libraries and databases started to become the new alternative of yester year's physical libraries. Ever since then, many organizations and publications started providing online sources and information in the form of online learning institutes [15]. Currently online courses allow not only text materials, but also live and recorded audio/video lectures, forums, discussions groups for class etc. Hybrid courses are also being offered that have both online and in class lectures, thus using the internet platform efficiently[15].

\subsubsection{Science Websites}

There are many science websites that are available online that allow users to access information about science and new science breakthroughs. Over the time, number of such websites has increased. Millions of people access these websites each month to gain knowledge. The below Table 1[17] provides the most popular websites currently and the number of unique monthly visitors.

Table 1 Science websites and number of visitors.

\begin{tabular}{|l|l|l|}
\hline S.No. & Name of Website & Number of unique monthly visitors \\
\hline 1 & HowStuffWorks & $19,500,000$ \\
\hline 2 & NASA & $12,000,000$ \\
\hline 3 & Discovery & $6,500,000$ \\
\hline 4 & LiveScience & $5,250,000$ \\
\hline 5 & ScienceDaily & $5,000,000$ \\
\hline
\end{tabular}




\begin{tabular}{|l|l|l|}
\hline 6 & ScienceDirect & $3,900,000$ \\
\hline 7 & Space & $3,500,000$ \\
\hline 8 & ScientificAmerican & $3,300,000$ \\
\hline 9 & Nature & $3,100,000$ \\
\hline 10 & PopSci & $2,800,000$ \\
\hline
\end{tabular}

Most of these websites have information divided into specific categories. Users can choose these categories as per their area of interest to gain access to the scientific information. Information is provided in the form on text, illustrations, pictures, audio and videos. However, these websites have much less number of visitors when compared to regular entertainment/social networking websites based on Table 2[18].

Table 2 Social Networking websites and number of visitors.

\begin{tabular}{|l|l|l|}
\hline S.No. & Name of Website & Number of unique monthly visitors \\
\hline 1 & Facebook & $1,860,000,000$ \\
\hline 2 & YouTube & $1,000,000,000$ \\
\hline 3 & Instagram & $600,000,000$ \\
\hline 4 & Twitter & $313,000,000$ \\
\hline 5 & Reddit & $234,000,000$ \\
\hline 6 & Vine & $200,000,000$ \\
\hline 7 & Pinterest & $150,000,000$ \\
\hline 8 & Ask.fm & $160,000,000$ \\
\hline 9 & Tumblr & $115,000,000$ \\
\hline 10 & Flickr & $112,000,000$ \\
\hline
\end{tabular}

\subsubsection{Online Forums}

Online forums allow discussions on the forum website where people can post messages and interact with one another [19]. These online forums allow people to hold discussions in real time overcoming the 
geographical barrier. Although not all online forums are used for learning, some of them are learning oriented [11]. Online forums allow people to communicate and discuss about their topics of interest, but previous research [11], [13] has shown that learning in online forums is lesser than what we see in video conferences, discussion groups. However, these online forums allow people to gain more knowledge complimenting the formal education [13]. Interacting in online forums allows people to share ideas as a part of a creative cognitive process rather than substantial measurable knowledge acquisition. This allows people to understand different mindsets, and shape their own ideas as well [20]. Online forums and discussions also allow people to get exposed to and understand higher level of information which comes because of interacting with others and expressing their views [21]. There are many online forums and message boards that are currently active like Yahoo Message boards, Stack Overflow, Quora, Answer bag etc.

\subsection{TWITTER}

Twitter is a microblogging platform which allows users to share with the world about anything. Twitter can be accessed either from the Twitter website or any mobile applications [8]. Twitter has specified a character limit of 140 (at the most) on the posts that can be shared. Twitter has its own unique terms, that are explained in the Twitter glossary [22] and each of them have a significance in using the website. The character restricted posts on Twitter are called as tweets [23]. These tweets are posted to a Twitter timeline of a user. They can be accessed in real time like a live stream of information [8].

People can create accounts on Twitter with a username, just like on any social networking website and post tweets. A Twitter user's account can be followed by other Twitter users to see their tweets. The people who follow any user's Twitter account become their followers and can send each other messages termed as 'direct messages'. Tweets can be liked by tapping on the heart icon below the tweet, which will let the author of the tweet know that their tweet has been appreciated. If we wish to share someone's tweets with our friends on Twitter, the tweet can be forwarded. This is termed as a 'Retweet' by Twitter. If we wish to mention someone in the tweet, it can be done by writing the username with a prefix of '@'. A 'hashtag' is a keyword. It is used to search for tweets which contain the same keyword. Any word which has a prefix of '\#' symbol is called a hashtag [22].

Hashtags allow people to classify their tweets into categories [24] and make them available for others who are looking for tweets on that particular topic [8]. This allows users to search for and view tweets of people whom we do not necessarily follow. This feature allows people to search for trending or required topics and have discussions with fellow Twitter users. This feature of Twitter is crucial in creating the Twitter 
community today which is full of discussions and information sharing. For the most part it allows users to get the information they want to share, out in the public and accessible to those who are interested in it.

\subsubsection{Twitter usage for learning}

According to Grosseck [25], Twitter can be used in many ways for education. Some plausible uses for Twitter for learning or in education are to build a community in the classroom, promote and allow collaboration among peers from anywhere, reach out for opinions on one's work, using it for references or for research purposes or reference for services like library services of a university etc. Twitter also facilitates a personal learning network, where people can communicate and ask questions to people whom they know. Twitter is already being used by educators for microblogging. This allows creating a community among peers. Educators say that Twitter serves as an effective and resourceful backchannel [26].

According to Trinkle [27], Twitter allows user to build their own Professional Learning Environment (PLE) or Personal Learning Networks (PLN). Twitter users can create their PLE by following the Twitter accounts of people or organizations that they wish to follow and can also control which users follow their personal account. This allows users to control what type of content or information that they allow themselves to be exposed to. Twitter allows users to join a community of their field of interest and participate in collective enquiry and information sharing.

Microblogging websites like Twitter allow informal learning [28]. Microblogging allows users to give immediate feedback. It also allows for documentation of all the content shared and interactions. Thus, it allows users to go back and monitor or analyze the content shared in the educational setting. The informal setting of such websites allows users to learn by reading the tweets of their interest and then by commenting and discussing about them. The learning on such websites is very transparent and one can monitor individual contributions when working on a project.

\subsubsection{Twitter for scientists}

As reported in [29], scientists and scholars can use social media websites like Twitter to enhance their professional profile, and information regarding their work. Scientists have started using social media to advertise their ideas and opinions, share information about conferences, their research collaborations etc. In addition to these uses, some researchers [29] have said that the number of article downloads has increased when they started to tweet about their research articles; thus, increasing their credentials when measured through the traditional metrics. This adds to the author's performance when ALMetrics (author level metrics) is used which considers usage, rating, social connectivity etc., as measuring factors[30]. Although it is not clear if tweeting increases number of citations in a long term, it has been seen that tweeted articles 
have 11 times more chances of being cited by others. Twitter uses less amount of time when compared to traditional blogging since the posts are short. Twitter allows information filtering and thus scientists can share and access content about their field of research.

The article [31] talks about scientists and public outreach. Studies show how scientists communicate with the public (especially K-12 students on this article). Most outreach activities seem to be in the form of presentations offered at their workplace or otherwise. There is also a lot of involvement in the form of judges in competitions and tutoring. There is a class of activities titled "Others" by the authors which seem to suggest that scientists use other channels to help educate. However, this survey was done in 2005, a time when social media was rather not so extensive and penetrating as it is these days.

The article [32] talks about the absence of open data sets in most disciplines of science and technology. The author claims that scientists, while publishing their data, think of the data sets they have used as byproducts and do not expect these byproducts to be made available to a larger set of audience in the form of open data sets. The author claims that the people and agencies that call for these data sets request only the data to be shared while scientists traditionally have been sharing data along with their interpretations of it. Thus, there is a lack of information sharing involving research data. According to [33], scientists have long had this habit of withholding results in academics and other disciplines. 


\section{NEEDFINDING AND PILOT STUDY}

As a part of background research and need finding, a pilot study was conducted on several scholars, scientists, professors, researchers, subject matter experts (SME) and students to find out the dynamics of scientific knowledge sharing between the scholars and public. The people considered for need finding are

- Scholars- Researchers, Professors

- Science Fans- Subject Matter Experts (SME), Experts (knowledgeable by personal interest)

- Novices-Students (Graduate students, Undergraduate students), Science Enthusiasts (Public interested in Science)

The main aim of these studies is to find out ways through which scholars and science fans (scientists and experts) are engaging with their followers (public) on Twitter and how students are using Twitter for learning. Drawing from this analysis, this study also involves building a system to guide scholars and science fans to share their knowledge with the general population. The following studies include the description of the study and the domain of people on whom the study was conducted following by the results obtained based on the pilot study.

\subsection{STUDIES}

\subsubsection{Study I- Collection of Twitter Usernames of Scholars and Science Fans}

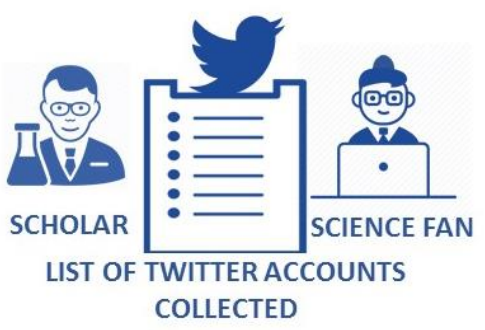

Figure 3-1 Figure showing the collection of Twitter usernames of Scholars \& Science fans

For Study I, it has been researched if there are scientists and subject matter experts using Twitter and aim is to retrieve a list of such accounts. For this, Twitter keyword search approach has been used. First, a list of potential fields of science and work titles has been documented, based on which the accounts and usernames can be searched. Using the Twitter search feature and the specific keyword for scientific field, the usernames of accounts related to the keyword have been listed out. Since Twitter can have fake accounts, the retrieved accounts have been briefly verified manually to check if the account is indeed of 
someone related to the field of science. By repeating the above steps, a list of 332 Twitter user profiles have been documented, which has been illustrated in Figure 3-1. The documented list includes, the name of the scientist or subject matter expert, their Twitter username and the science field they work on.

This list shows that there are indeed active users on Twitter who share content regarding their work. Popular researchers like Neil deGrasse Tyson (Astrophysicist) has 24 million followers, Brian Cox (Physicist) has 14 Million followers, Richard Dawkins (Biologist) has 1 Million followers. Although, these are the top people who are most popular on Twitter, there are many others who have Twitter accounts and are actively sharing with their followers. Scientists on Twitter also show that scientists of different fields have a Twitter account. By the observation of number of followers, number of tweets, it can be seen that the scientist accounts with most followers have more feedback in the form of retweets, likes and mentions.

\subsubsection{Study II- Scholars \& Science fans are requested to share short snippets of research work via tweet}

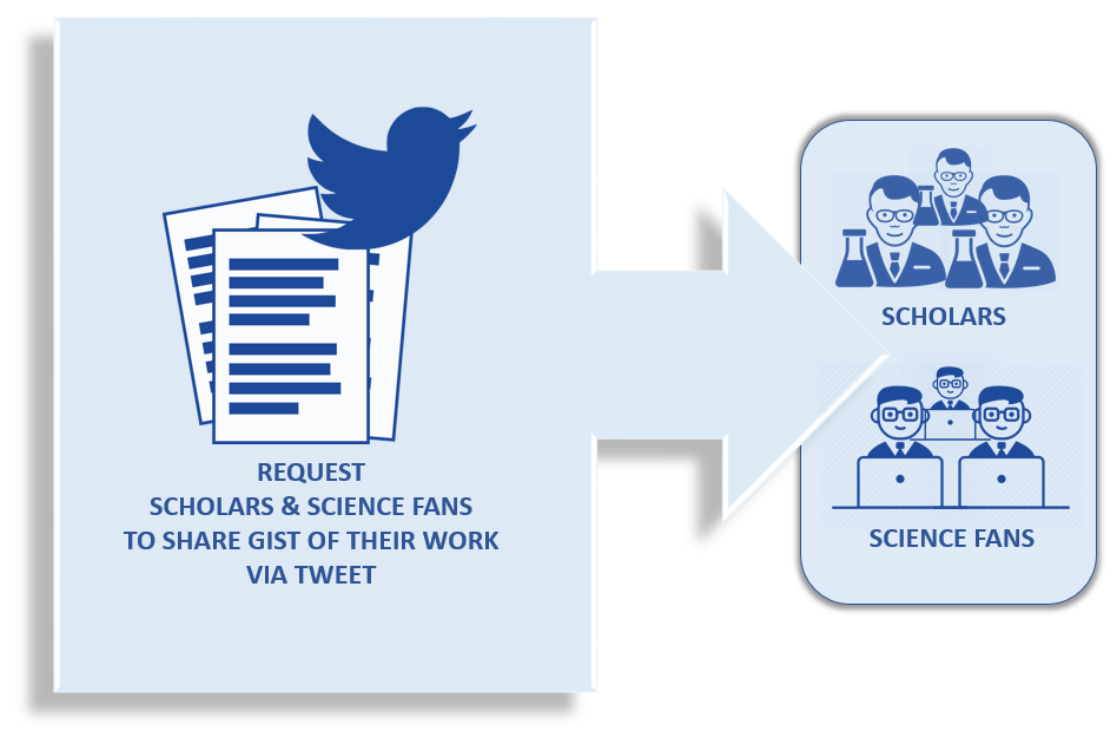

Figure 3-2 FIgure illustrating how Scholars \& Science fans are requested to share short snippets of research work via tweet

The aim of this study was to contact the scientists and SMEs on Twitter and get them to share briefly about their recent work related to the field they are working in which has been illustrated in Figure 3-2. For this study, the list of scientists and SMEs obtained in study I has been used. In order to contact the scientists on Twitter, a Twitter bot account has been created with the name @ ScienceIntellec. Figure 3-3 shows the bot profile that has been created for this study.

Using this account, users from the list have been tweeted and asked to share briefly about their work. Some generic messages that can be tweeted have been documented, such as 
Hi! Love your research on , Would you like to collaborate with regular people who are very interested in your area of research?

Hello! Congratulations on your recent research on , There is one brilliant way by which you can make more people recognize your work. You can do this by collaborating and reaching out to common people who are passionate about your area of research. Would you like to collaborate?

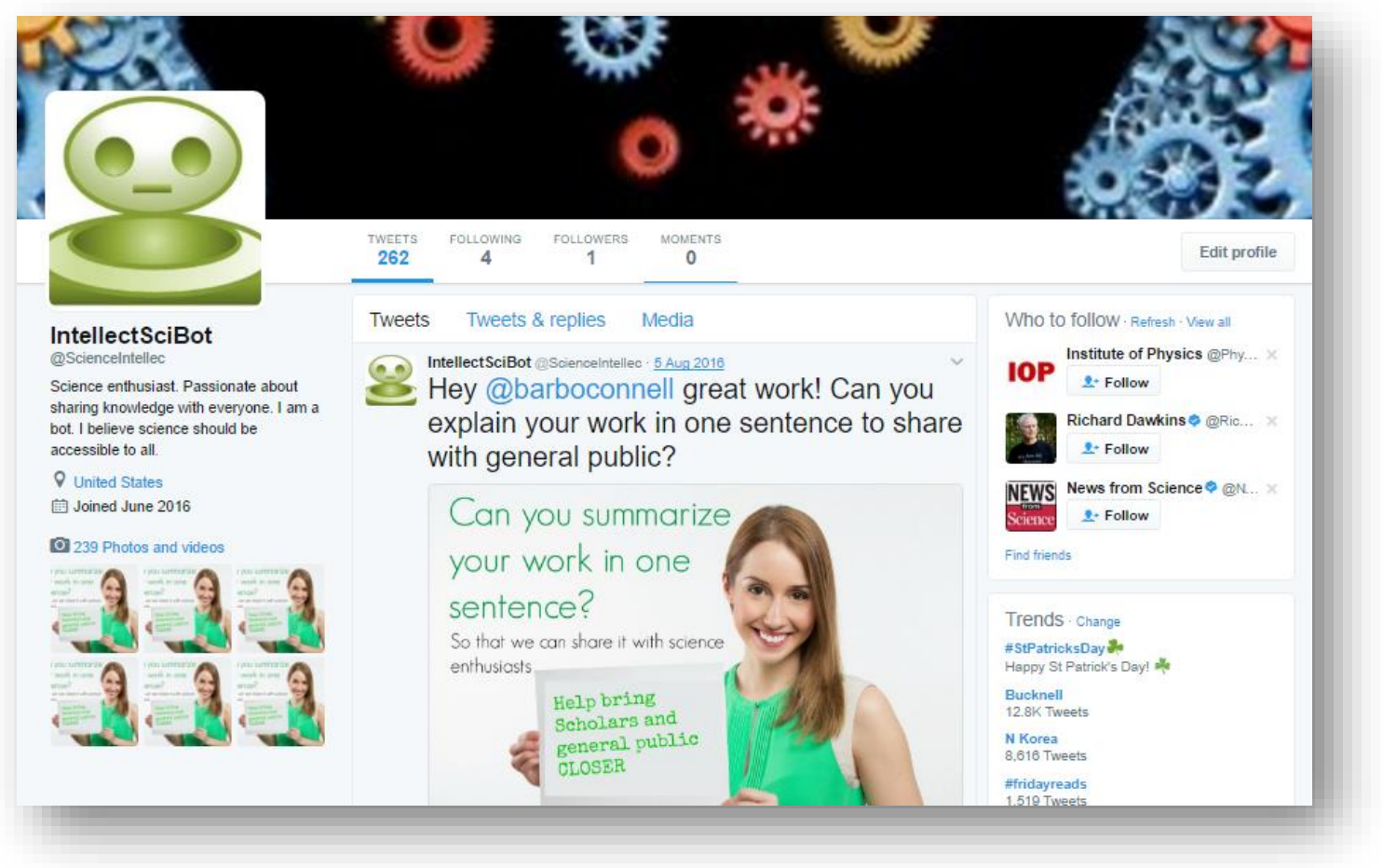

Figure 3-3 Bot Profile on Twitter

Excellent research on _. It is incredible that your work is well known within the scientific community. But if you do not interact with the common people, your work might not get the recognition it deserves. There is a way in which you can reach out to science enthusiasts passionate about your research area. Are you interested?

Greetings! I love your recent research on Do you wish your work becomes well recognized worldwide? You can popularize your work by reaching out to the regular people who are very interested in your area of research. Do you want to try to reach out? 
To meet the character requirement, the following tweet message has been selected. Tweet is of the form 'Hey@Twitter_user_name great work! Can you explain your work in one sentence to share with general public?'. Figure 3-4 shows the tweets sent manually to scientists.

IntellectSciBot@Sciencelntellec·31 Jul 2016

Hey@RichardDawkins great work! How would you summarize your

work in one sentence that can be shared with general public?

47

॥l

IntellectSciBot @Sciencelntellec·31 Jul 2016

Hey@elakdawalla great work! Can you explain your work in one sentence so that I can share it with general public?

\& 27 ill

IntellectSciBot @Sciencelntellec·31 Jul 2016

Hey@sapinker, great work! Can you please summarize your work in one sentence so that I can share it with science enthusiasts?

4

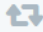

○

॥l

IntellectSciBot @Sciencelntellec·31 Jul 2016

Hey@ianbremmer great work! Can you explain your work in one sentence so that I can share it with general public who is interested?

4

Ł7

ill

Figure 3-4 Tweets sent manually to Scholars \& science fans

These tweets, did not receive any responses in the form of likes, retweets or mentions. Therefore, to gain attention and increase the number of responses, the tweets that were posted next were posted with an attached image. The attached image briefly describes the aim of the bot. The Figure 3-5 shows the screenshot of the tweet with an image attachment and the response received for the tweet.

Overall 262 tweets were sent out using the bot and as a result the bot received 10 mentions, 6 likes and 1 follower. Figure 3-6 shows the statistics of the tweets sent to scientists and the responses received. Although, the tweets, got positive responses from the scholars \& science fans, there was also negative feedback. Some scientists did not respond efficiently, and most of them did not respond at all. 


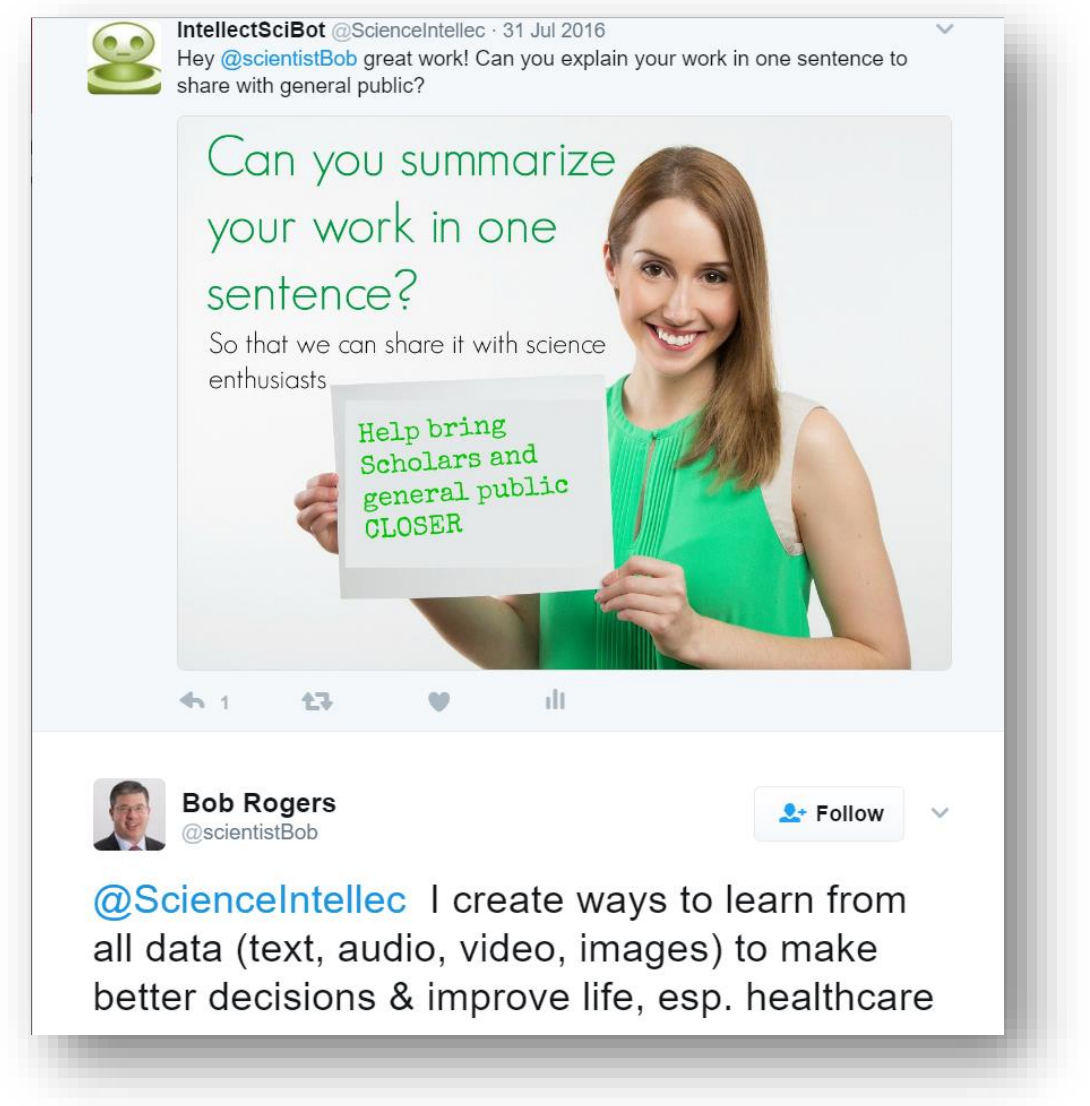

Figure 3-5 Tweet with Image attachment and its response

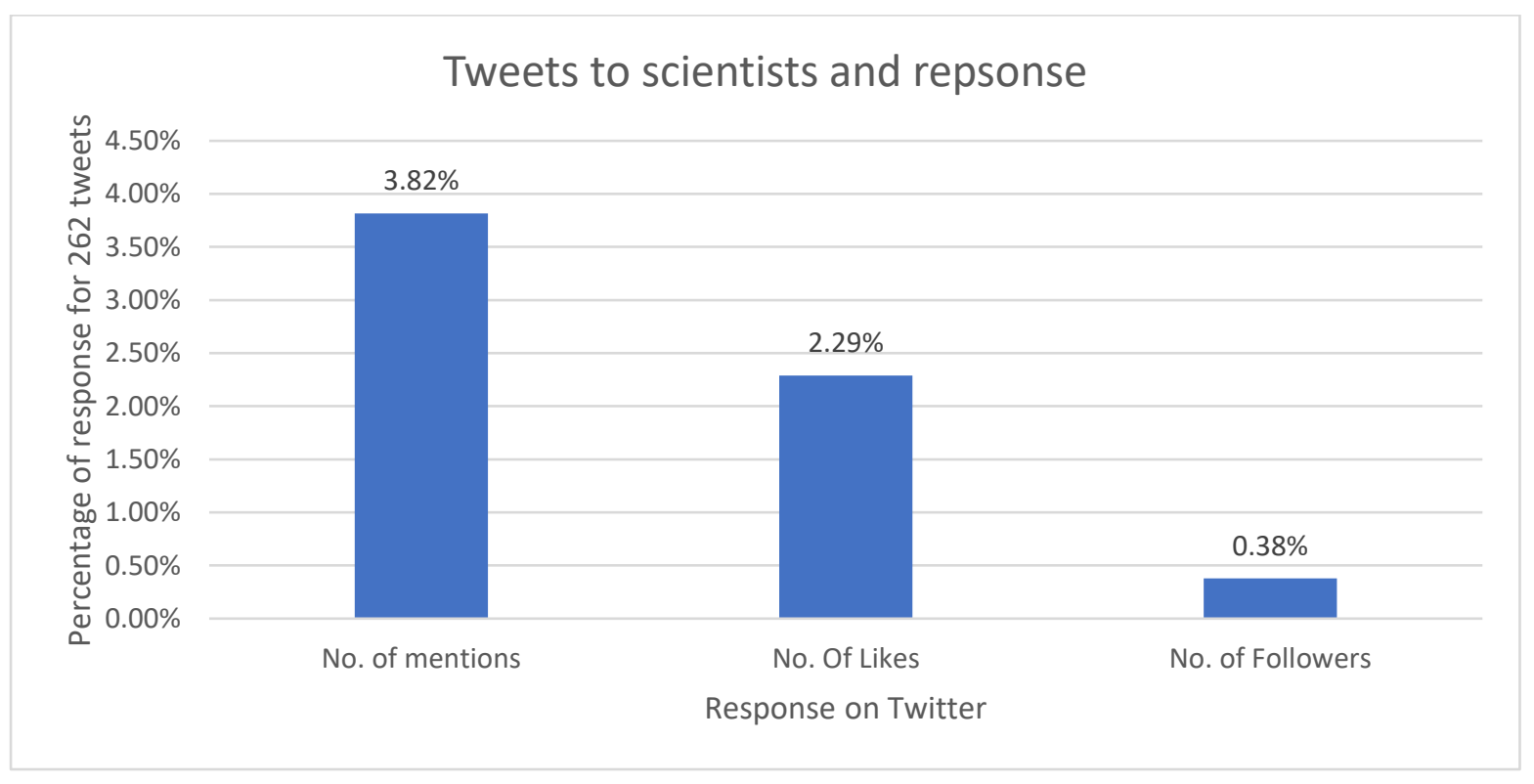

Figure 3-6 Statistics of Tweets to scientists and responses received 


\subsubsection{Study III- Interviews of Scholars and Science fans}

Because of the poor response obtained in Study II, a new study was conducted. The aim of this study was to interview the scientists, SMEs, researchers and professors. The main objective of this study is to find out how interested or disinterested are scholars \& science fans to share content to promote their work and educate the public. As a part of this study 22 professors at WVU, SMEs in industries and researchers have been interviewed which has been illustrated in Figure 3-7. They were asked if they used social media for sharing about their work. The responses received have a good balance between positive and negative opinions. The statistics of the scientists sharing on social media study are shown in Figure 3-8.

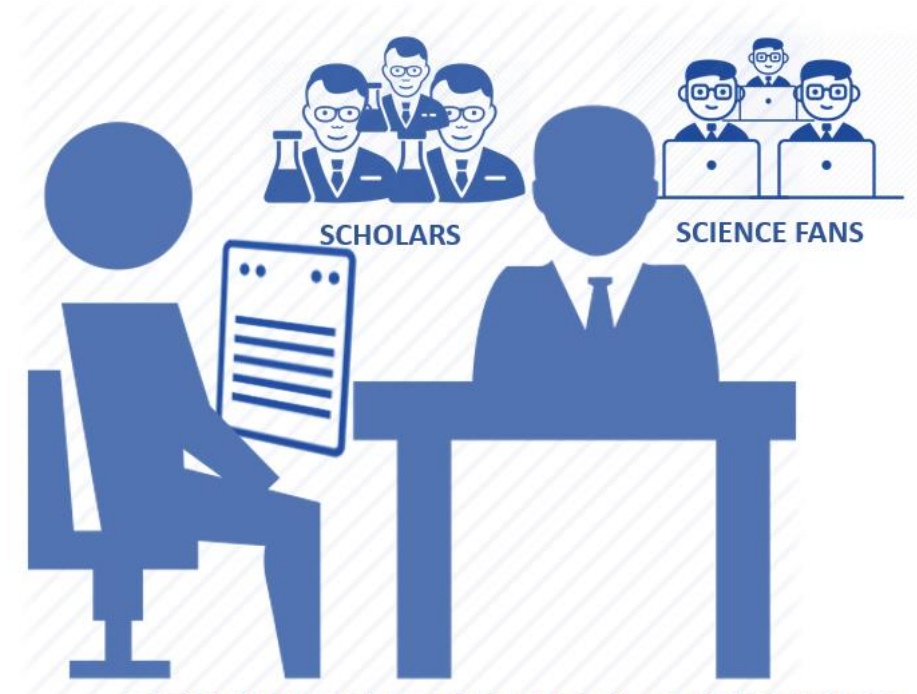

INTERVIEWING SCHOLARS \& SCIENCE FANS ABOUT THEIR INTEREST IN SHARING KNWOLEDGE ON SOCIAL MEDIA

Figure 3-7 Figure illustrating the interviews of scholars and science fans

Some of the professors think sharing about their work on social media allows them to get volunteers, share their opinions on research etc. But, most professors think that social networking is a waste of time and is only for the younger generation. They do not want to share information with public, as they feel their area of work would not be relatable to common man, or that he would not understand even if they did share. Some feel that only if there is potential benefit to public, only then they would want to know or read about their research or the content that they share. Some scientists find it time consuming and are unable to take out time from their busy schedules to maintain a social networking account and post content frequently. Some of them feel it would violate their intellectual property, hence they would only want to publish their work in the good scientific journal. 
However, some of them were open to share short summaries in simple terms of the work they do, or of their research papers, if a platform existed and there was good positive feedback. Ultimately, nobody wants to put in extra effort to share on social media unless there is a visible and quantifiable incentive for the content they share.

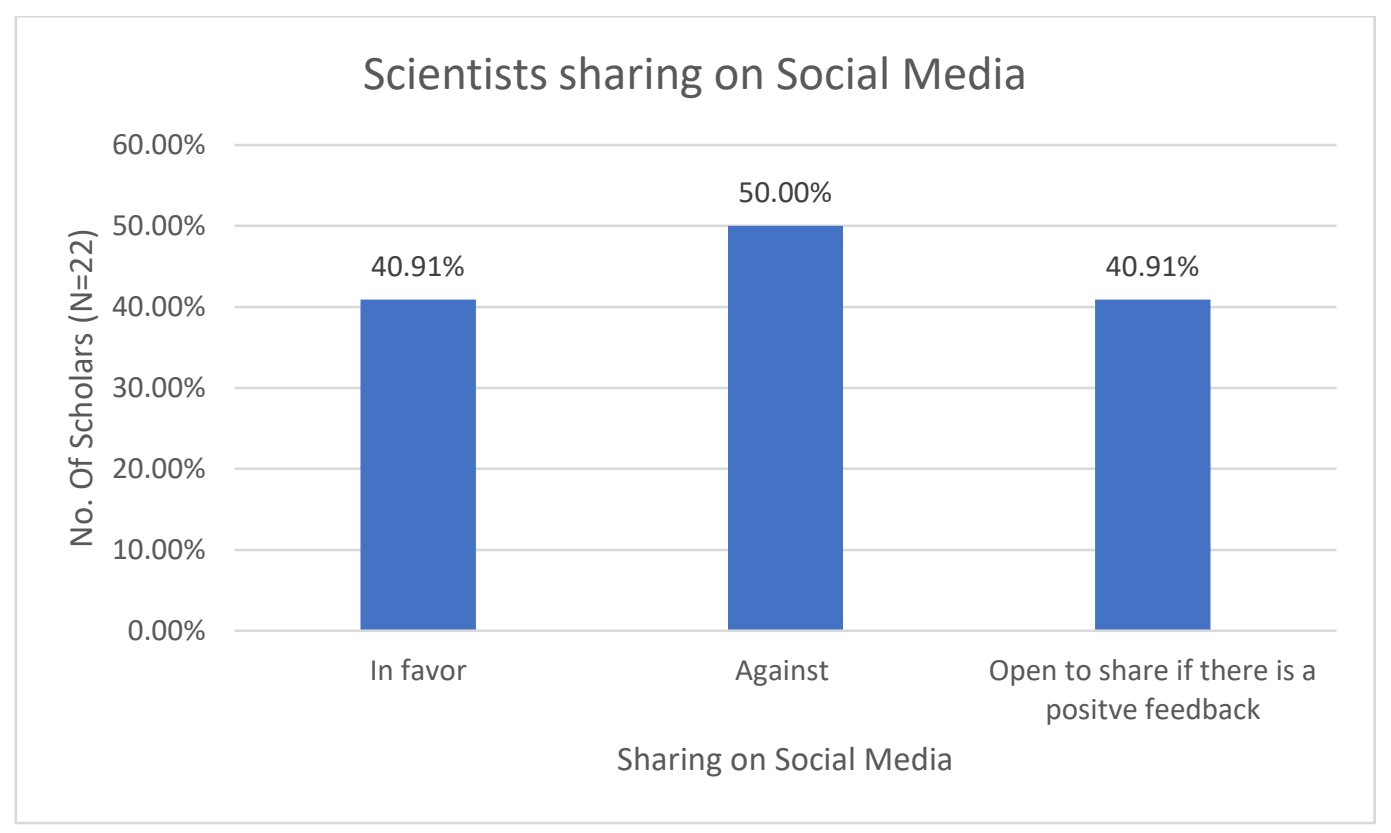

Figure 3-8 Statistics of the scientists sharing on social media

\subsubsection{Study IV}

The aim of this study is to interview Graduate students who are doing research. The objective of this study is to find out how interested are these graduate students in using social media for learning, resource sharing and interacting with peers and scholars \& science fans. As a part of this study 20 graduate students at WVU have been interviewed which has been illustrated in Figure 3-9. The students were asked about their opinion on using social media for learning, interacting and sharing scientific knowledge. They were asked about problems they faced in their early research period as well as in the current time. They were specifically asked to share about problems they faced when it comes to identifying their field of interest for research and while conducting literature review for their current research.

Statistics of graduate students and their usage of social media for learning is shown in Figure 3-10. Most of them say they use social media for learning, looking up for information which is connected to their field of interest. Some of them are interested in the fields other than their core area just to keep themselves updated with the new research developments. Some of them follow popular scientists and science organizations on Twitter and Facebook to receive RSS feed posted by them. They also like it because they can get to know 
about conferences these scientists attend, so that they can go back and learn more about the conference online.

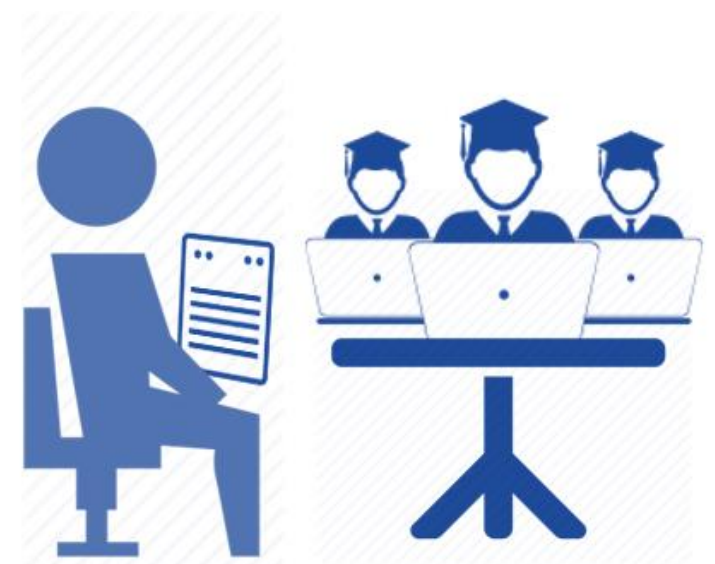

\section{INTERVIEWING GRADUATE STUDENTS ABOUT THEIR SOCIAL MEDIA USAGE FOR LEARNING}

Figure 3-9 Figure illustrating the interviews conducted on graduate students

Most of them feel that there are no quick responses from the scholars \& science fans. Also, some of them expressed their concern that there is no measure to check if the content these scholars \& science fans share is reliable. As graduate research students, some of them would like to connect to scholars \& science fans in their field of interest so that they can get hold of good resources to get motivated and aid their research work. Some of them shared their experiences of how seminars, videos and interacting with peers, etc. drew them to their topic of research rather than books and research papers.

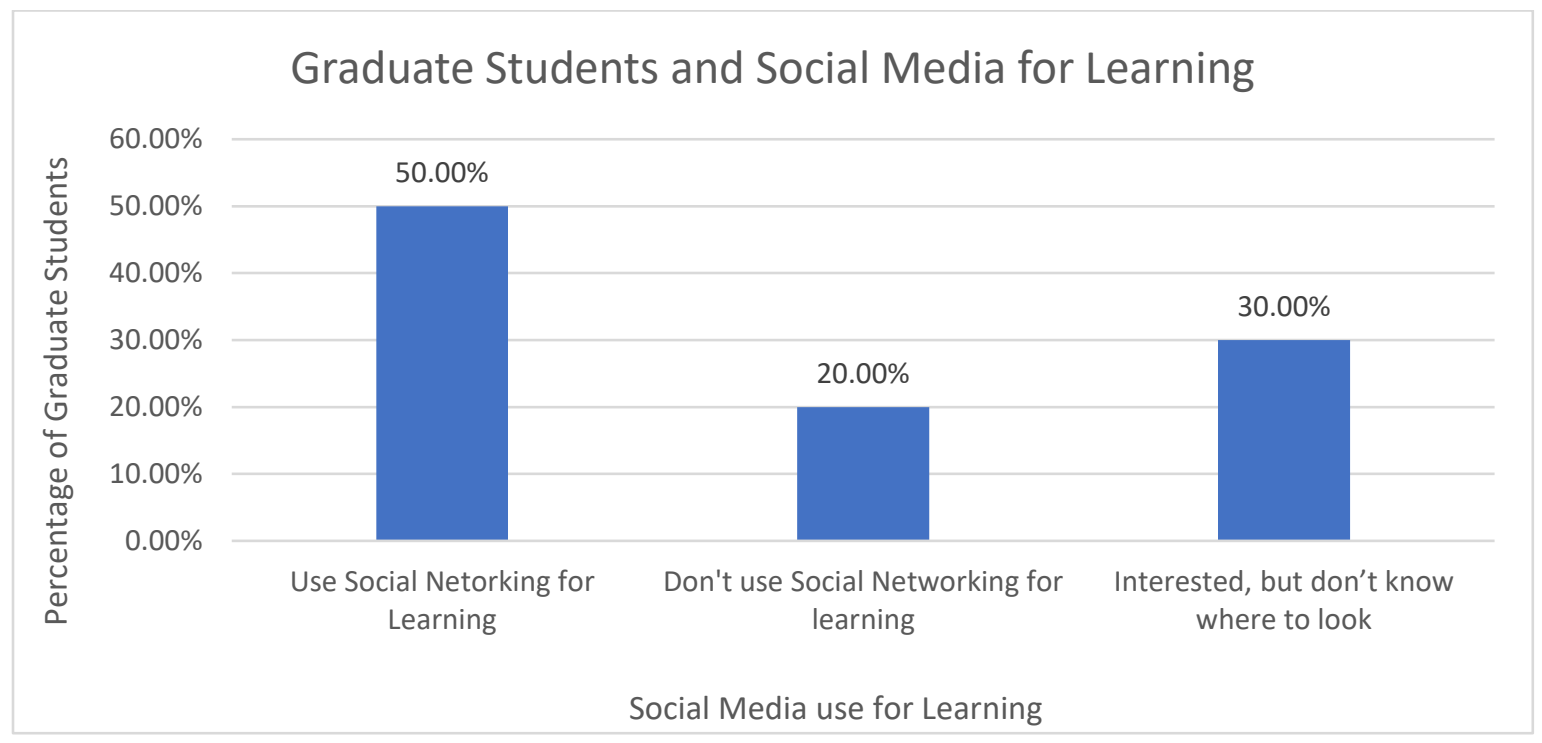

Figure 3-10 Statistics of graduate students' usage of social media for learning 


\subsubsection{Study V}

The aim of this study is to interview the Undergraduate Students (Freshman and Sophomores). Since most undergraduate students who are freshman and sophomores will not be involved in highly technical research work, they were chosen to be interviewed. The objective of interviewing such undergraduate students is to get information about how they are using social media for learning which has been illustrated in Figure 3-11.

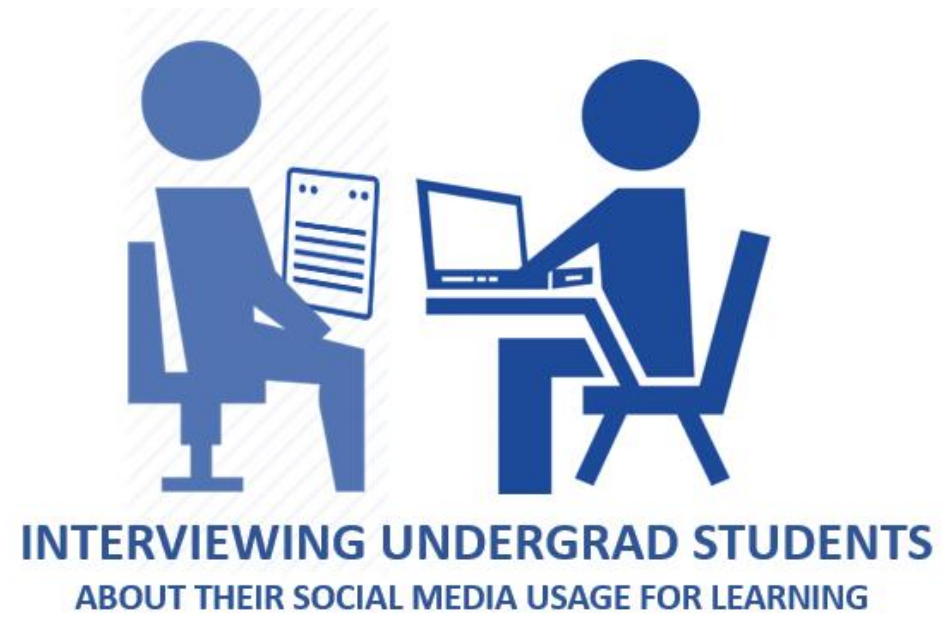

Figure 3-11 Figure illustrating the interviews conducted on undergrad students

For this study, N=52 Freshman and Sophomore students at WVU were interviewed. At first, undergraduate students were asked questions mentioned in the Figure 3-12 below. They were asked questions regarding their usage of Internet and Social media for learning. They were also asked about the research sources and what they think about them.

Statistics of Undergraduate students and their usage of social media for learning is shown in Figure 3-12. Most of the students use Internet for learning. However, most of them feel that they are not updated with the current research that is being conducted. Most believe that the complicated terminology used in these research papers is beyond their understanding. Even though there is an abundance of research articles available through the scientific databases, most of the students find those papers very complicated. Most of them admitted that if a short summary was provided to them about the research papers of their field of interest, then they would be motivated to look further into that topic or refer to the research paper and explore further. 


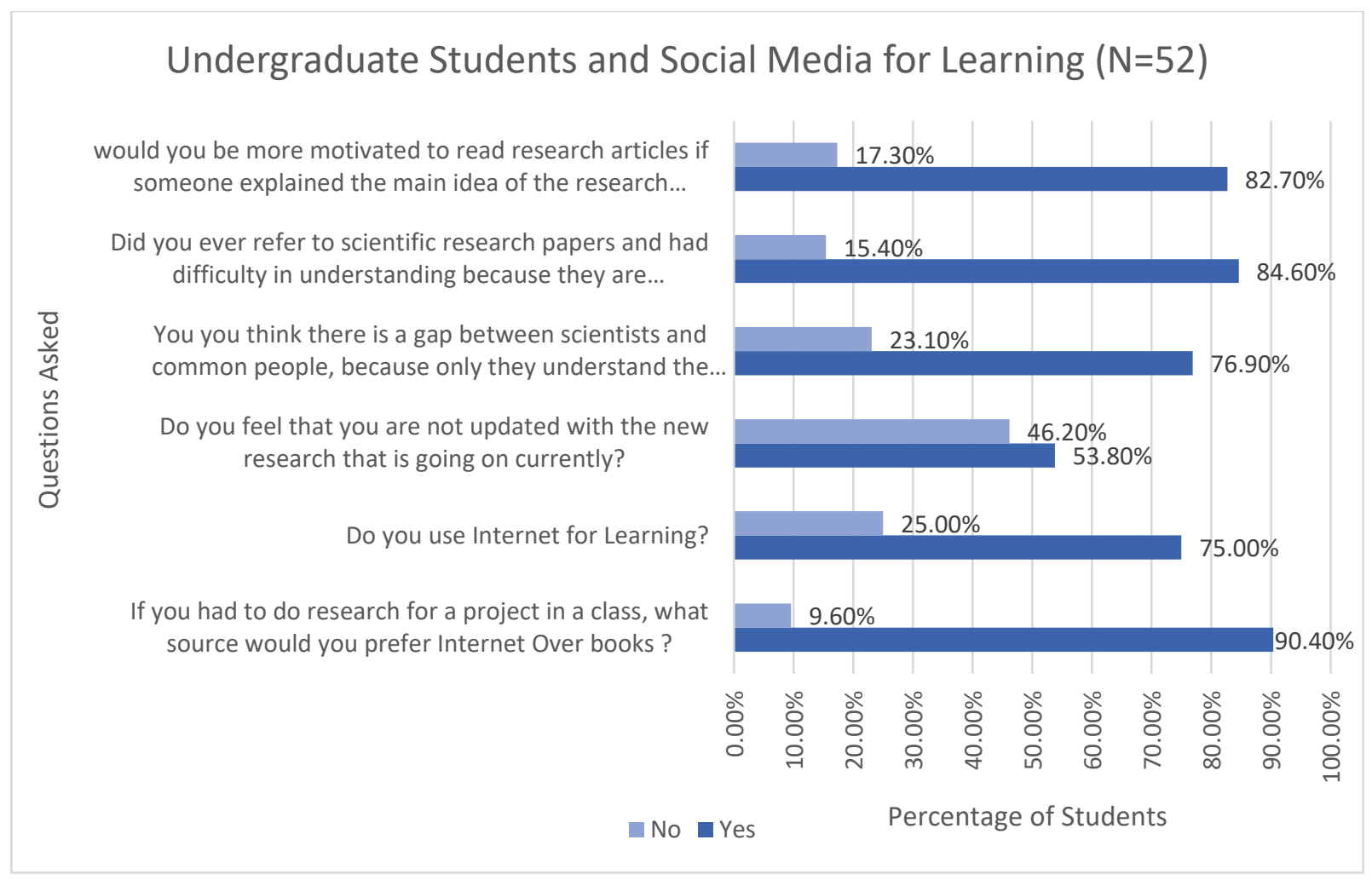

Figure 3-12 Statistics of Undergraduate students' usage of social media for learning

Then students were asked about their usage of Twitter for learning. Statistics of Undergraduate students and their usage of Twitter for learning is shown in Figure 3-13 Most of the students have Twitter accounts. Most of them are open to interact with their fellow students and scholars \& science fans to get more knowledge. When students were asked about their interest in receiving tweets with short summaries about research papers of their favorite field, $50 \%$ of them showed interest. 


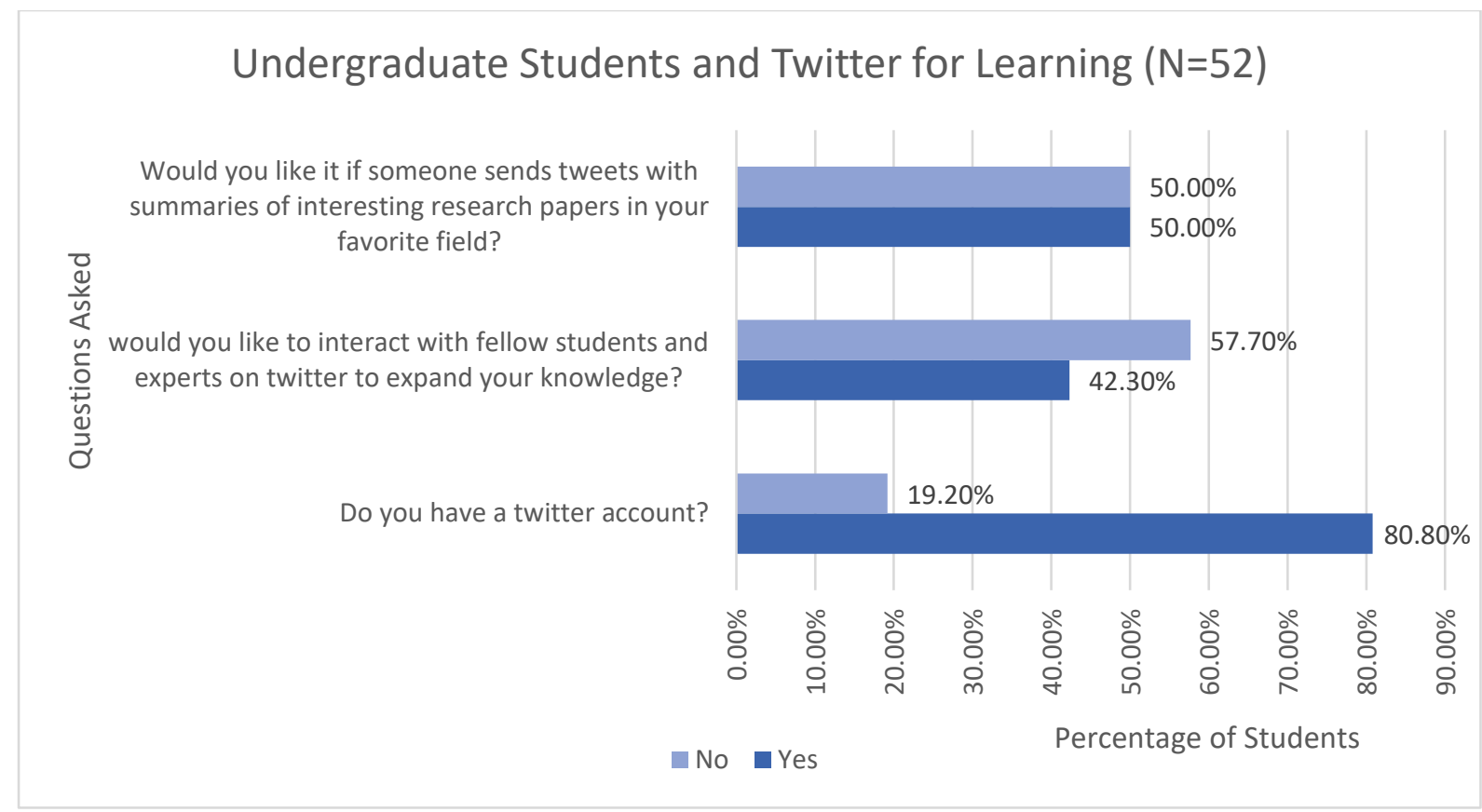

Figure 3-13 Statistics of Undergraduate students' usage of Twitter for learning

\subsubsection{Study VI}

The aim of this study is to see if reading a simple short summary would motivate novices to read the abstract or entire research paper. A pilot was performed with an initial group of undergraduate students which has been illustrated in Figure 3-14. A survey was conducted among a group of 78 freshman and sophomore students from West Virginia University asking about 'Data Clustering'. The participants were exposed to a journal article written by a renowned scholar. The participants were then assessed to find out if it was easy to understand the given article. For those of the participants that were not interested to read the article, a question was posed to ask them if they would be interested to read a simple short summary describing the article. The simple short summary was showed to them and then a measure of how many students were interested to read the original article was assessed using the survey. Figure 3-15 shows the results of the pilot study conducted. It was found from this survey that the simple short summary raised the interest in as many of 50 percent of the cases where the participants had originally showed no interest to read the article. The survey also assessed what might be the reasons for students not wanting to read the article in the first place. The answer to this question was not surprisingly the length of the article but the technical jargon used in the article which demotivated the students to read further.

The numbers in Study III, IV, V and VI are not statistically significant. The responses given may vary depending on the specific field of science and people. 


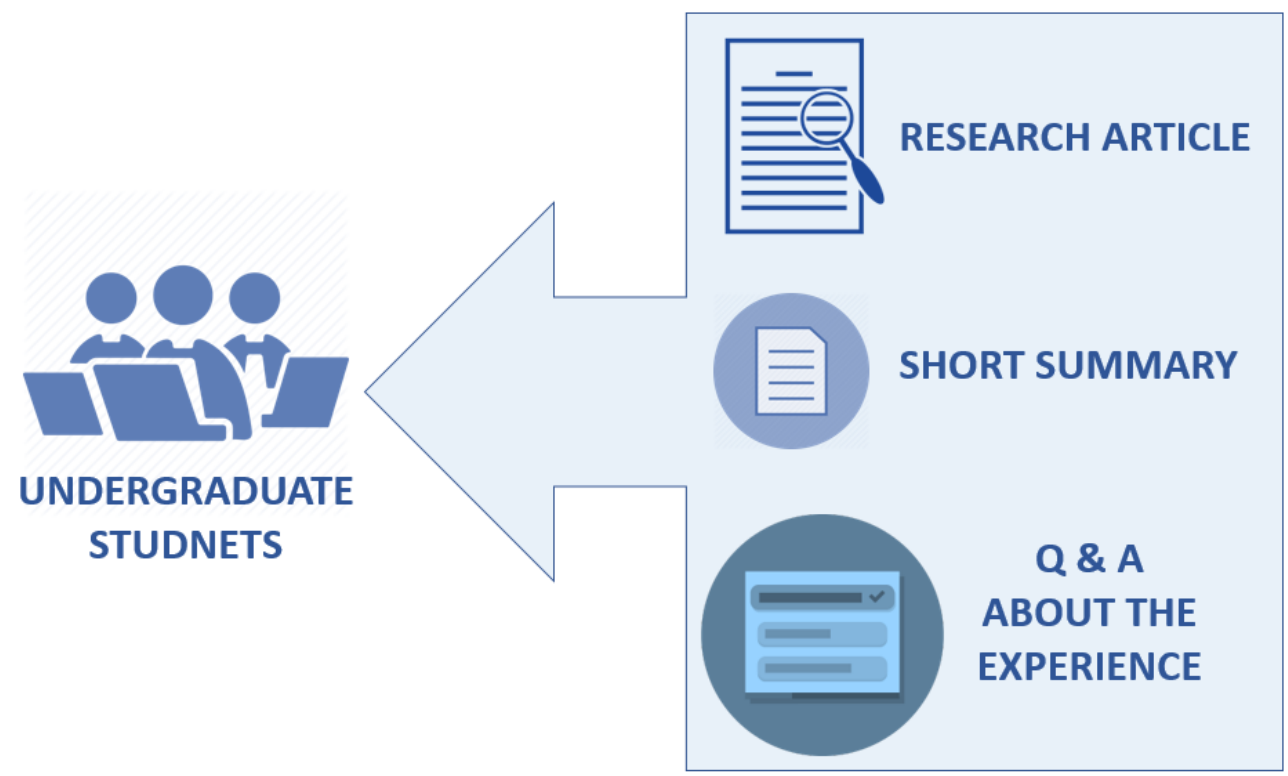

Figure 3-14 Figure illustrating Pilot study

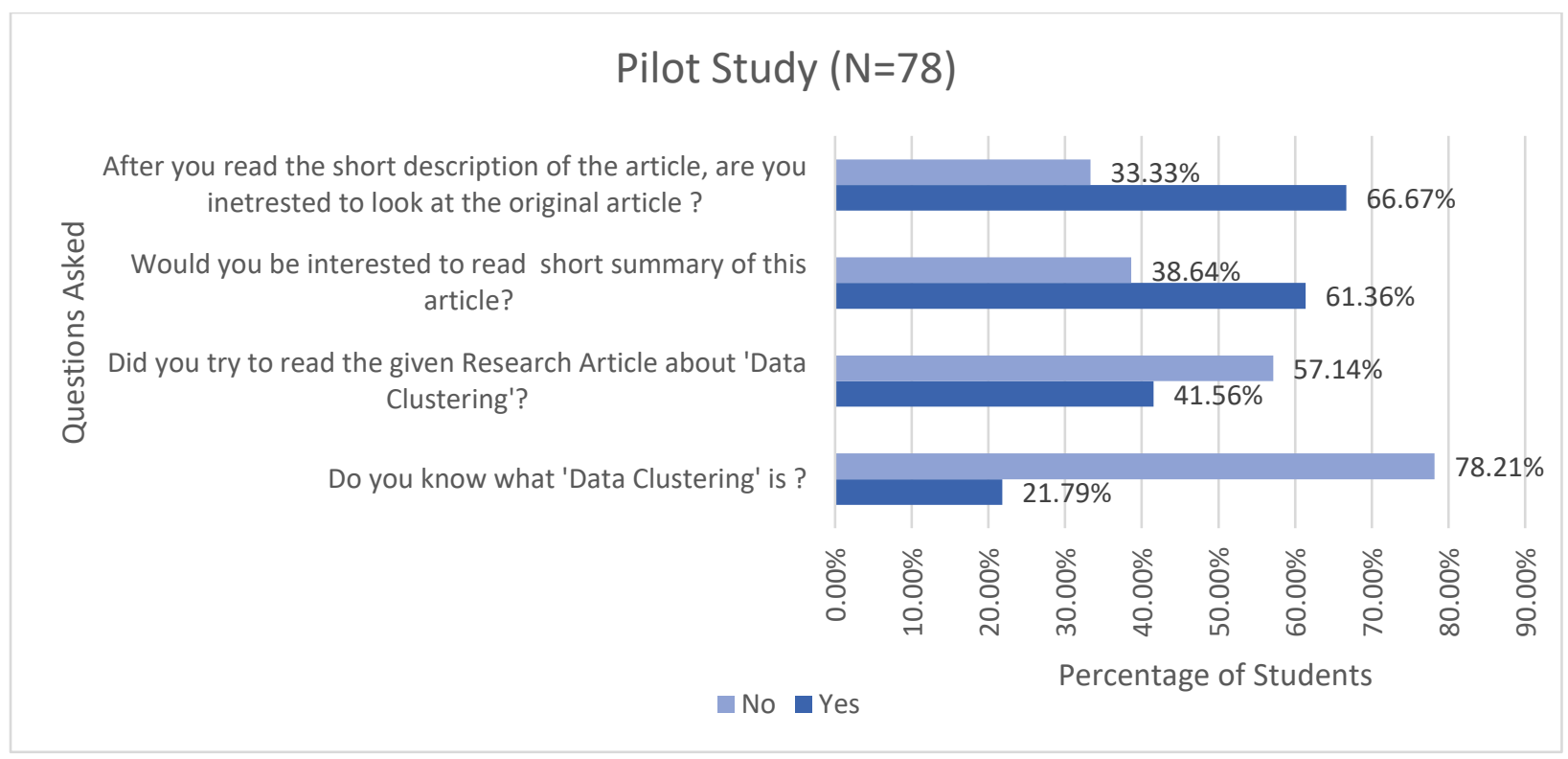

Figure 3-15 Pilot Study 


\section{SYSTEM}

\subsection{IDEA BEHIND BUILDING THE SYSTEM}

Considering the need finding, pilot studies and other studies that were done manually (mentioned in the previous sections) and on Twitter the following was evident. Scholars (and science fans) were generally not motivated to share knowledge on Twitter. Most scholars \& science fans point to the factor of time indicating that it requires considerable amount of time to process the information from a technical article and create a tweet-style message. Many scholars \& science fans also identified the need for motivation. They were not sure if such a system would be used by a novice user. However, they agreed about the increase in motivation if a novice user seems to be interested in the topic. They said that they would be interested and motivated to share the short summary if they can receive some kind of incentive or see a quantifiable positive feedback which would motivate them to share often and also keep track of what topics are of interest to the novices.

Based on studies IV, V and VI, most of the novices have a Twitter account. Most of them are interested to update themselves with the research that is going on currently. Although they are hesitant to refer to research articles that are very complicated to understand, students showed interest in reading the short description or summary of research articles in the field they are interested. Novices are more likely to read the short summary if they intrinsically show interest in a field of science. This can be identified by looking at the tweets they have posted with a keyword or hashtag mentioning the field of interest. For example, someone who just posted a tweet and mentioned 'microbiology' would more likely be reading the short summary given to them rather than some random Twitter user who would disregard the tweet as spam.

To tackle the aspect of lack of motivation among scholars and science fans to share, the aspect of feedback has been added to the system. If the novices like the short summary they read, they are requested to retweet, like and follow the science fan and in turn the scholar associated with that tweet. The scholars and science fans can then measure which topics receive good feedback and tweet more about them in the future and stay motivated.

Thus, a system is proposed to counter the gap between the elite scientific community of scholars, science fans and the novices. We use crowdsourcing to tackle the time-consuming section of this activity, which is creating a tweet-style message. Thus, the system allows a method for scholars (and science fans) to interact and share knowledge with novices and motivate them. It also in turn helps them to gain popularity and enhance the citations and downloads of the research work. 


\subsection{STEPS IN THE SYSTEM}

\subsubsection{Collection of List of Science Fans and Scholars}

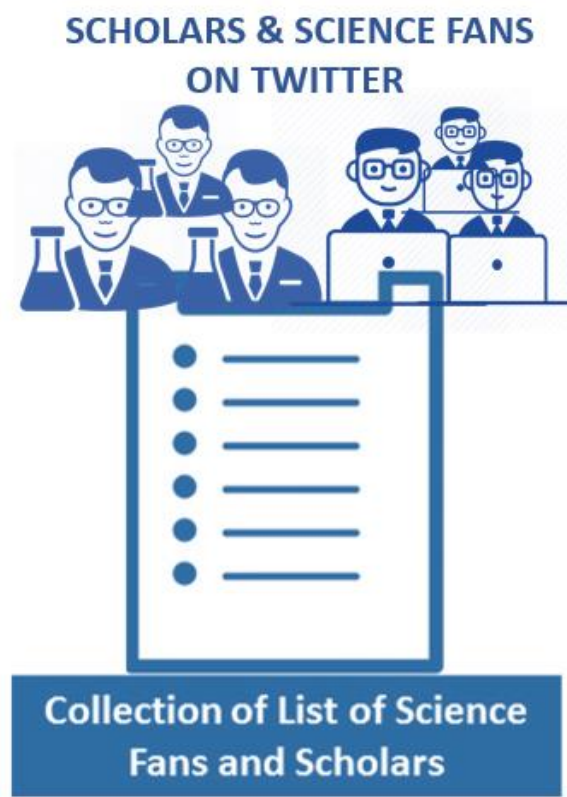

Figure 4-1 Collection of List of Science Fans and Scholars

To start with the system that we proposed, we require a list of potential scholars and science fans who would have good knowledge in the area that they work in. Hence, we searched for people in a specific field who are actively sharing content in Twitter. We formulated the list of such scholars and science fans by using keywords pertaining to different fields. The list for this step has been obtained by doing Study I. This approach gave us a list of people on Twitter whom we could approach to move on to the next step of our system.

\subsubsection{Requesting Short Summary of Favorite Research Paper}

A Twitter bot is then created on Twitter using which we can tweet automatically using python code. Once we collected a list of scholars and science fans on Twitter, we contacted them through the bot. The bot tweets to them asking them to share a short summary of any research paper that they are very familiar with. This way the science fan or scholar need not put in much effort to give the short summary since they chose their favorite research paper, that is any article that they know very well. 


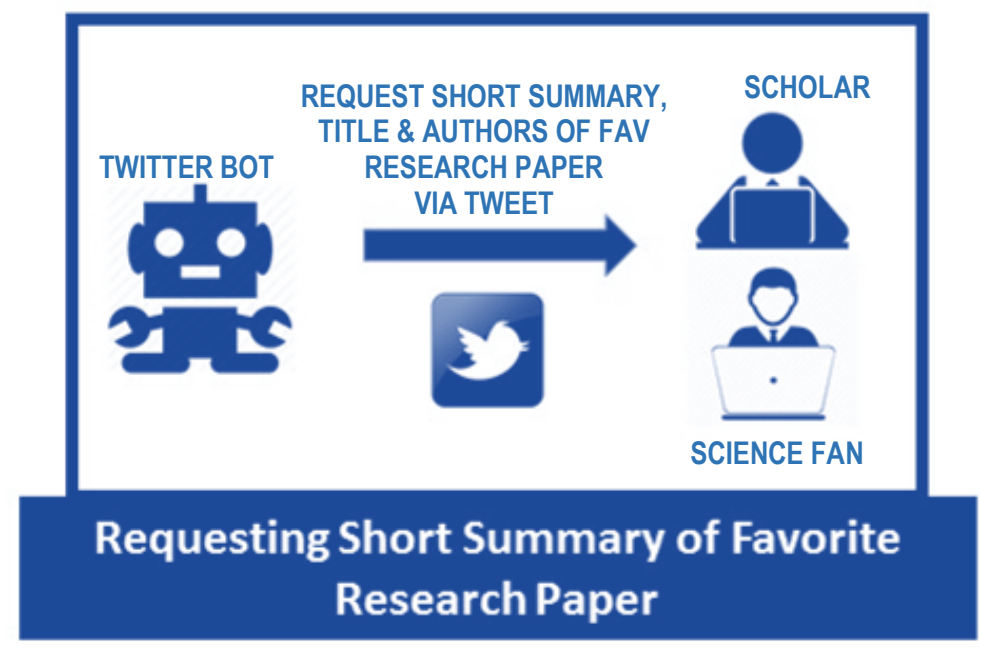

Figure 4-2 Requesting Short Summary of Favorite Research Paper

\subsubsection{Short Summary is sent to the Bot}

The bot requests the scholars or science fans to share a short summary of their favorite research paper. Those tweets are sent to the respective science fans or scholars. They respond to the bot with a short summary and the title of the research paper of the field of their interest. These replies from scholars and science fans are stored. These replies are segregated and stored based on the field or topic that has been mentioned.

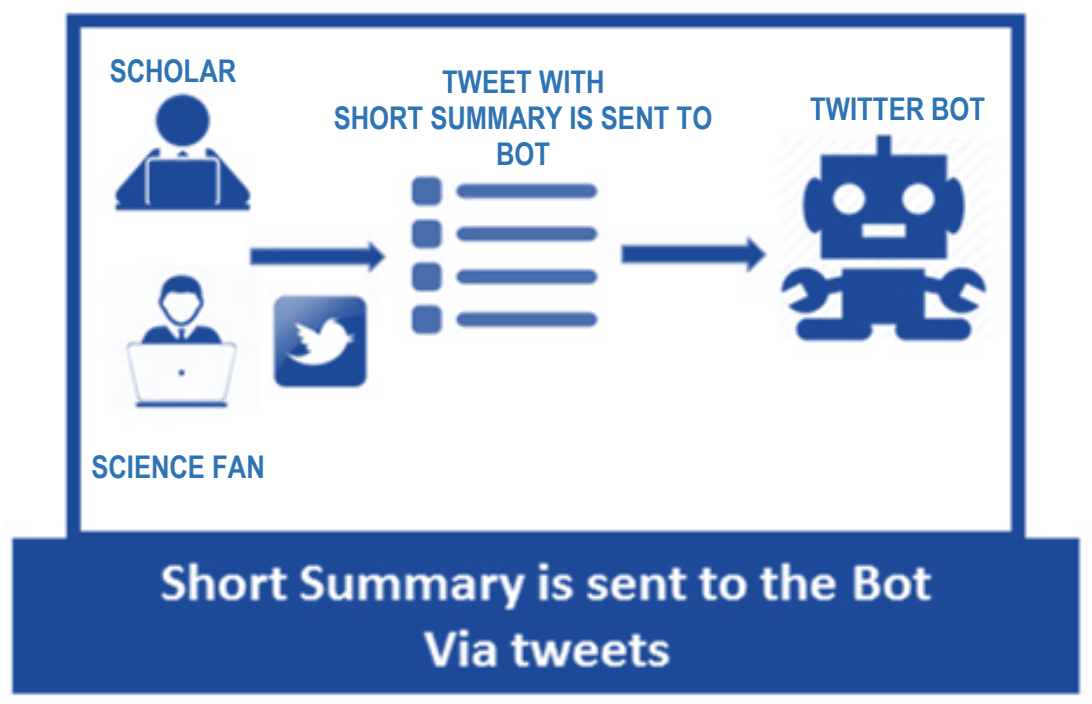

Figure 4-3 Short Summary is sent to the Bot 


\subsubsection{Collection of List of Novices}

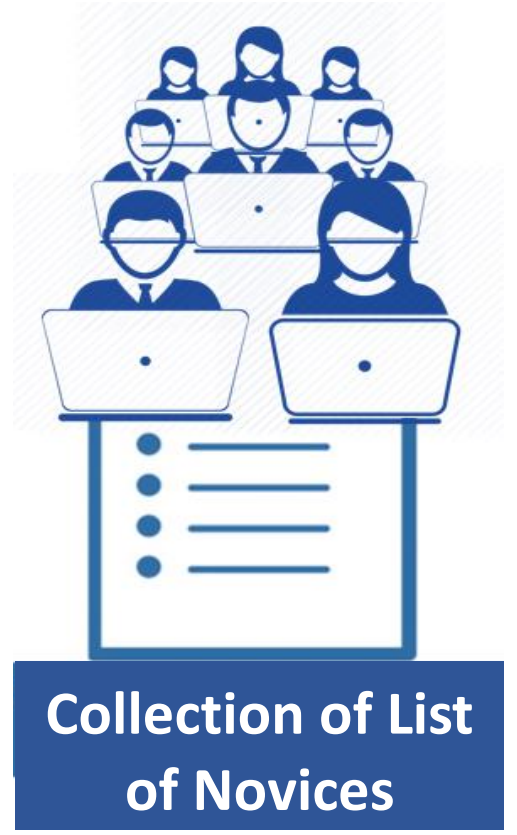

Figure 4-4 Collection of List of Novices

Parallelly, based on the responses and summaries received, a list of novices is formulated. We search Twitter using keywords and collect tweets about a certain topic. From the collected tweets, the list of usernames is collected. Now this is the list of people who are interested in a particular topic since they are tweeting about it. It is more efficient and useful if we forward the short summaries to people who are actually interested in a particular field, rather than randomly sending it to users who may or may not be interested in the field of which the summary talks about.

\subsubsection{Send Short Summary of a Research Paper to Novices}

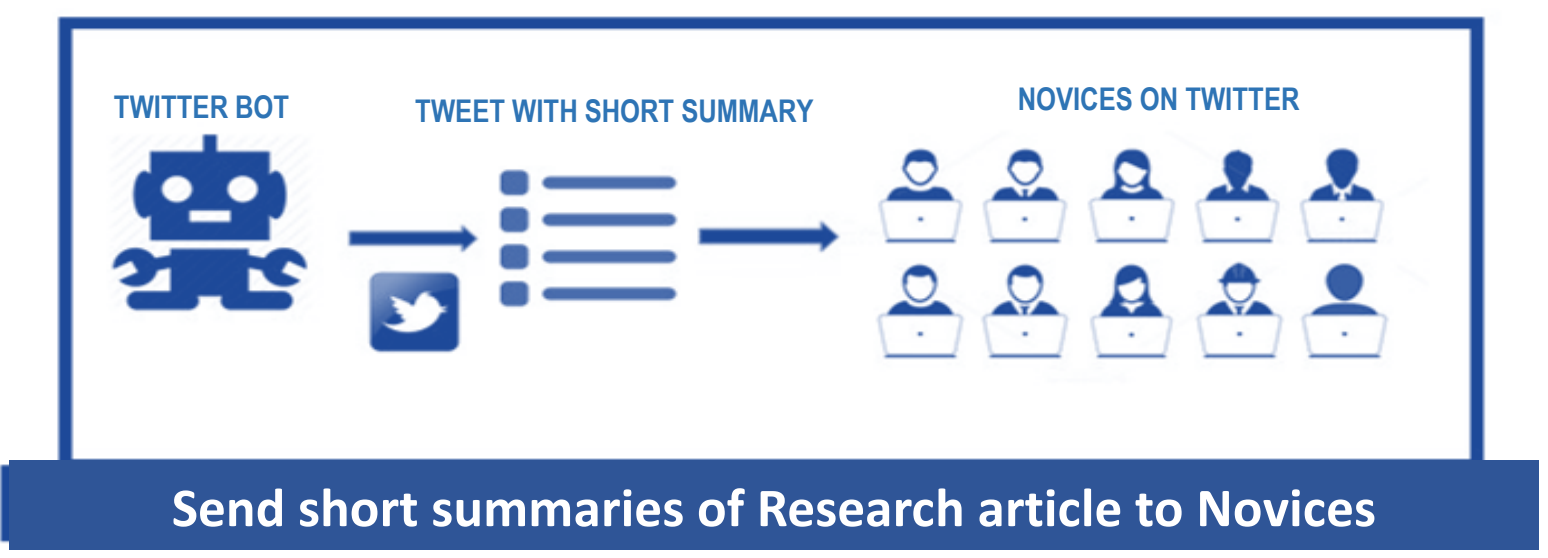

Figure 4-5 Send Short Summary of a Research Paper to Novices 
Once the list of novices is identified, the short summary of a certain topic, is sent to the corresponding naive user who is interested in that field. This is done by a series of tweets sent to the naive user. The first tweet contains the short summary of an interested topic. The next tweet provides the title of the research paper to which the short summary has been provided.

\subsubsection{Request Novices to Retweet Science Fan and Bot}

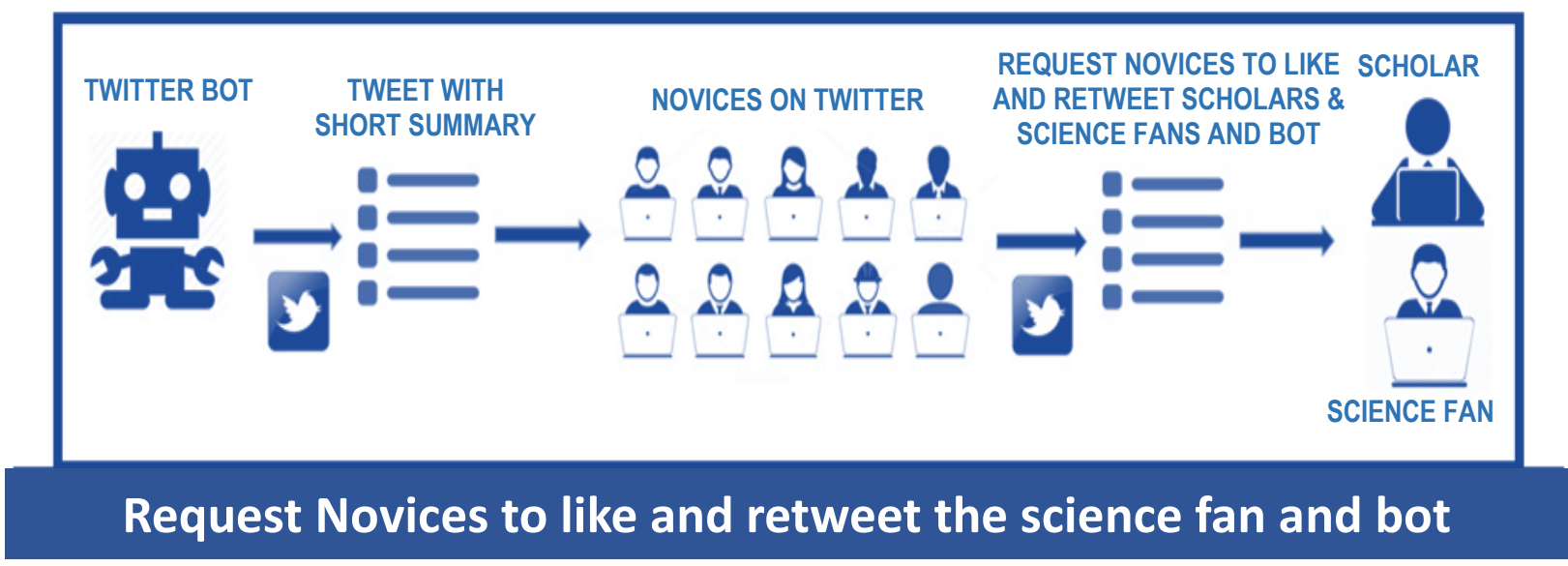

Figure 4-6 Request Novices to Retweet Science Fan and Bot

After the above two tweets are sent to the naive user, a third tweet is sent. The next tweet will ask and motivate the naive user to retweet the shared summary and retweet the science fan's or scholar's post. This way we create a feedback mechanism that will motivate the science fans to share more and more short summaries. At the same time, they get a chance to advertise their work and enhance the number of citations and article downloads. These short summaries are appealing to the novices which will in turn motivate them to consider and explore these scientific research areas.

\subsection{CONTROL FLOW OF THE SYSTEM}

The control flow of the system goes like this. First the list of potential science fans and scholars is documented. Then, as per the field of science a tweet is created to request the science fan to share a short summary or description of a research paper that they are familiar with, along with the research article title. The bot is used to tweet to the respective scholar or science fan. The scholar (or science fan) if interested, will create a short summary or description of a research article of choice and tweet to the bot. The bot will store the response under the category of the field it matches. Thus summaries and research article names are collected. The bot then identifies the usernames of novices who are tweeting about a science topic in real time. This is done by collecting a live stream of tweets using a hashtag and the keyword (science topic). 
The novices are then sent this short summary/decription. First the bot tweets the short summary/description to the novice. Next, the novice is sent the title of the research paper related to the short summary. The third tweet then requests the novice to like, retweet and follow the science fan or scholar assoicated with the research article. 


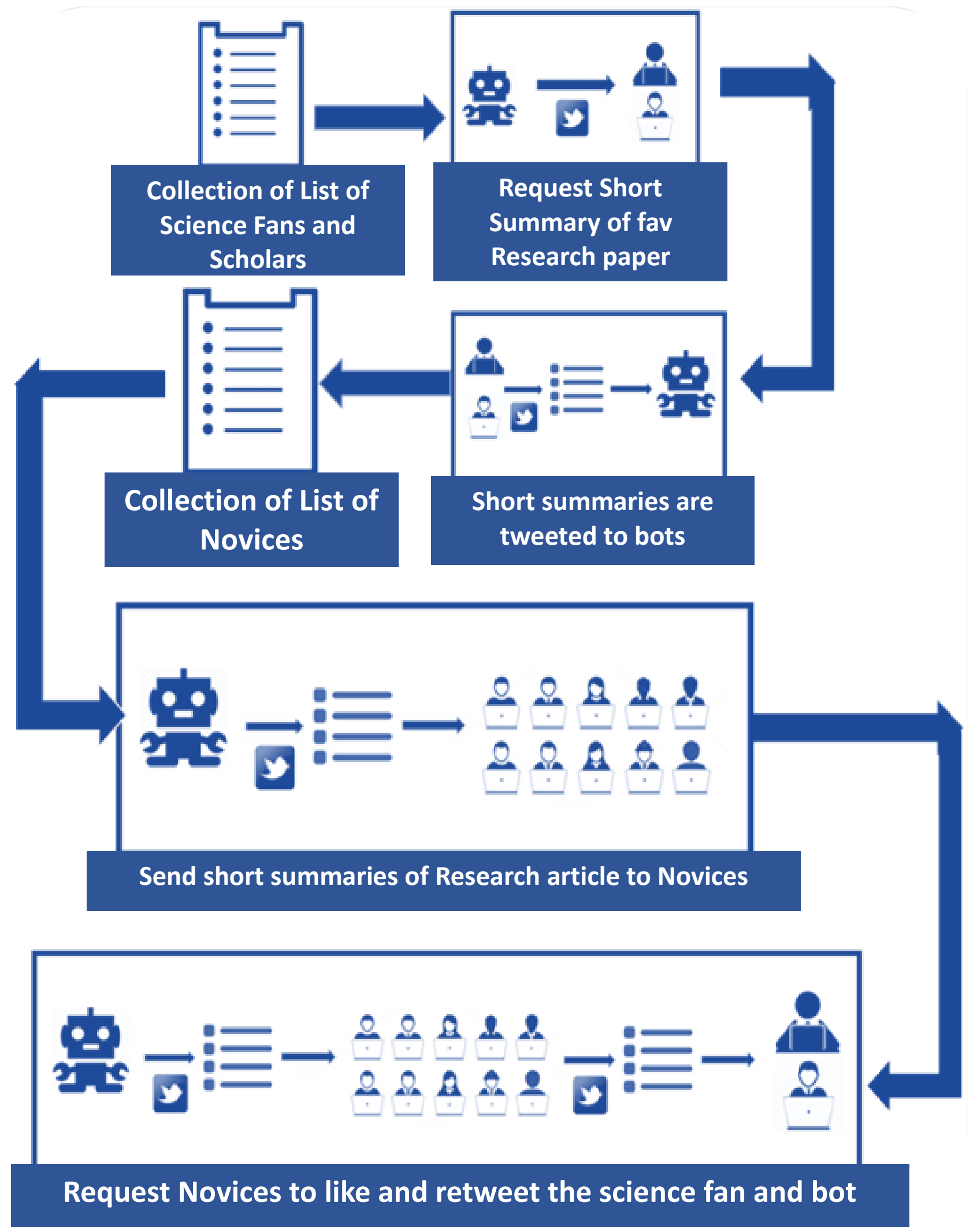

Figure 4-7 Control Flow of the System 


\section{IMPLEMENTATION}

\subsection{APPLICATION PROGRAMMING INTERFACE (API)}

An Application Programming Interface (API) gives protocols, tools, software components and a set of functionalities for an application software. These are designed to be independent of each other so that a programmer can use these building blocks either independently or in combination. An API makes the job of the software developer a little easier because they can use the ready-made objects and actions that might may needed to develop a software application[34].

\subsection{WEB API}

A web API is created and used for working with web browser or web server. A software company releases it API for a web based application or a web tool. The API is then made accessible for programmers and software developers to put together and design services or products using that respective software. It comes under web development. A web API can be used to access databases, and create Graphical User Interfaces (GUI). API does HTTP requests and gets responses in text format (either JSON or XML). Representational state transfer (REST) is being used in the recent times for web resources. Specifically, with respect to social media, these web APIs allow developers to create applications that allow to create content and share it simultaneously in various places on the internet[35].

\subsection{TWITTER API}

Twitter API is the API released by Twitter. It offers different APIs for different purposes. There is Representational state transfer API (REST API) used to read and write to Twitter using programs. Streaming API allows to retrieve Twitter data in real-time. Ads API is used by Twitter partners commercially, to advertise their product. There are more services offered by Twitter like embedding Twitter in other websites etc. For this problem report, REST API has been used and OAuth has been used to secure the process of Twitter API usage. The next subsections of the report will briefly describe the APIs used for implementation of the system.

\subsubsection{OAuth}

OAuth protocol is openly available and is used to give secured authorization for applications of websites, mobile etc. Twitter uses OAuth to allow developers to have an authorized access to the Twitter API[36]. OAuth functions as a mediator in behalf of the end user. It is used to allow third party services to use the user's account information (but keeps the password secret). OAuth gives access tokens to authorize a user account[37]. This is how the process works. At first, the resource owner gives permission to the third-party 
client via OAuth authorization server. The OAuth then gives access tokens i.e., credentials (client identifier, client secret and authorization code) for security for identifying user and logging in. These access tokens are then used (until they are revoked or expired) by the third-party client to view and use the resources of the resource owner[38].

\subsubsection{REST API}

Representational state transfer (REST) is a client-server communication protocol. REST API allows authorized third party clients to request, retrieve and modify (Read, update, write, delete, create) the data of a web service. It uses HTTP to send requests and gets the response with data in either Extensible Markup Language (XML), JavaScript Object Notation (JSON) or Hypertext Markup Language (HTML)[39]. Twitter REST API gives access to only those third-party clients and applications who are authorized using OAuth[40].

\subsection{TWITTER BOT CONFIGURATION}

A Twitter bot is a program which can be used to automatically follow user accounts and post/retrieve data or tweets from Twitter. To code a bot first we need to create an Twitter account for a bot on Twitter. The profile of the bot that has been created is shown in Figure 5-1. Once the account is created, an application is created from developer interface of Twitter (dev.Twitter.com).

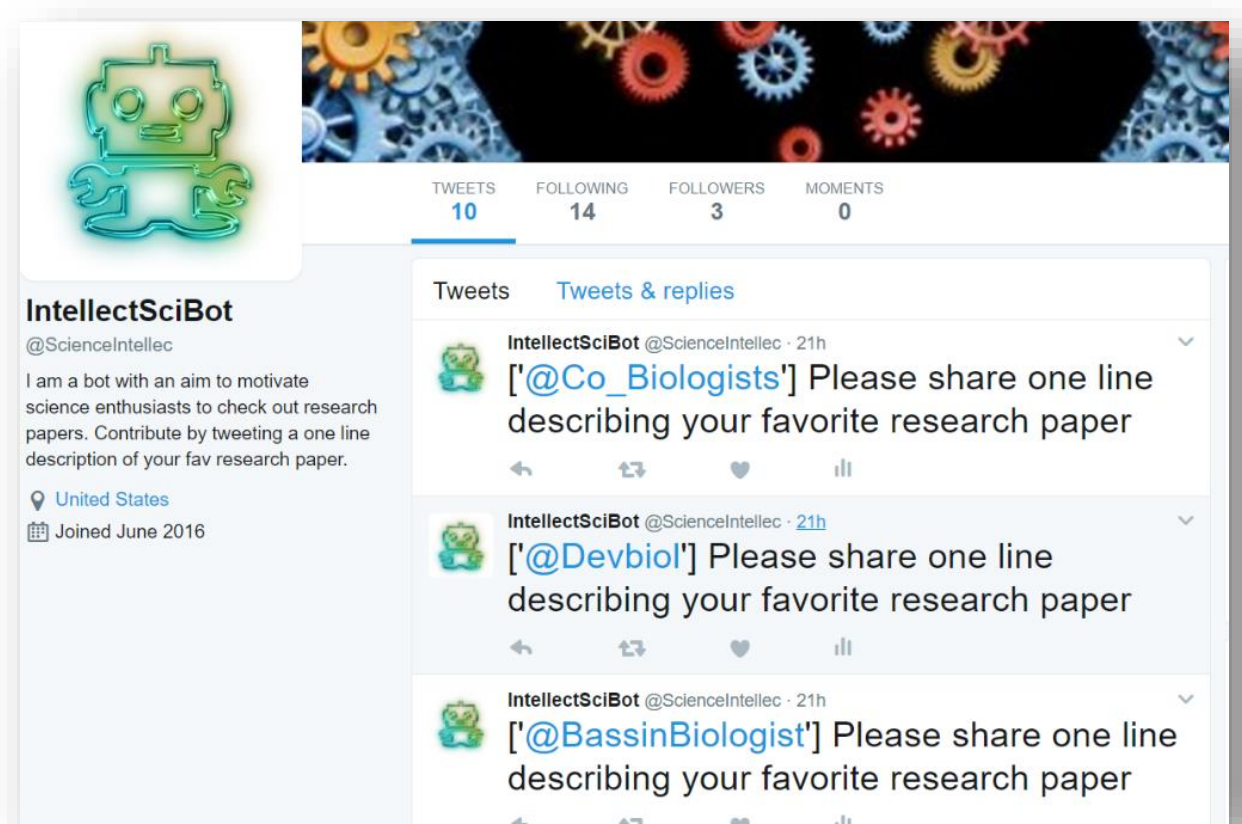

Figure 5-1 Bot account on Twitter 
Figure 5-2 shows the screenshot of the application created on the Twitter developer website.

\section{Scientists tweets}

Details Settings Keys and Access Tokens Permissions

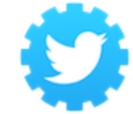

Collect Scientists tweets

https://Intellec.com

\section{Organization}

Information about the organization or company associated with your application. This information is optional.

Organization None

Organization website None

\section{Application Settings}

Your application's Consumer Key and Secret are used to authenticate requests to the Twitter Platform.

Access level

Read and write (modify app permissions)

Figure 5-2 Creating Twitter Application

By following the terms and conditions from Twitter we should fill all the required details for the bot and generate Consumer Key, Consumer Key Secret, Access Token, Access Token Secret. The Figure 5-3 shows the generation of access tokens for the application that has been previously created. In Application Permission model assign all the required permissions for the bot to perform required operations. The different types of permissions are Read Only, Read and Write, Read Write and Access Direct Messages. For this application required settings are Read and Write[41]. 


\section{Scientists tweets}

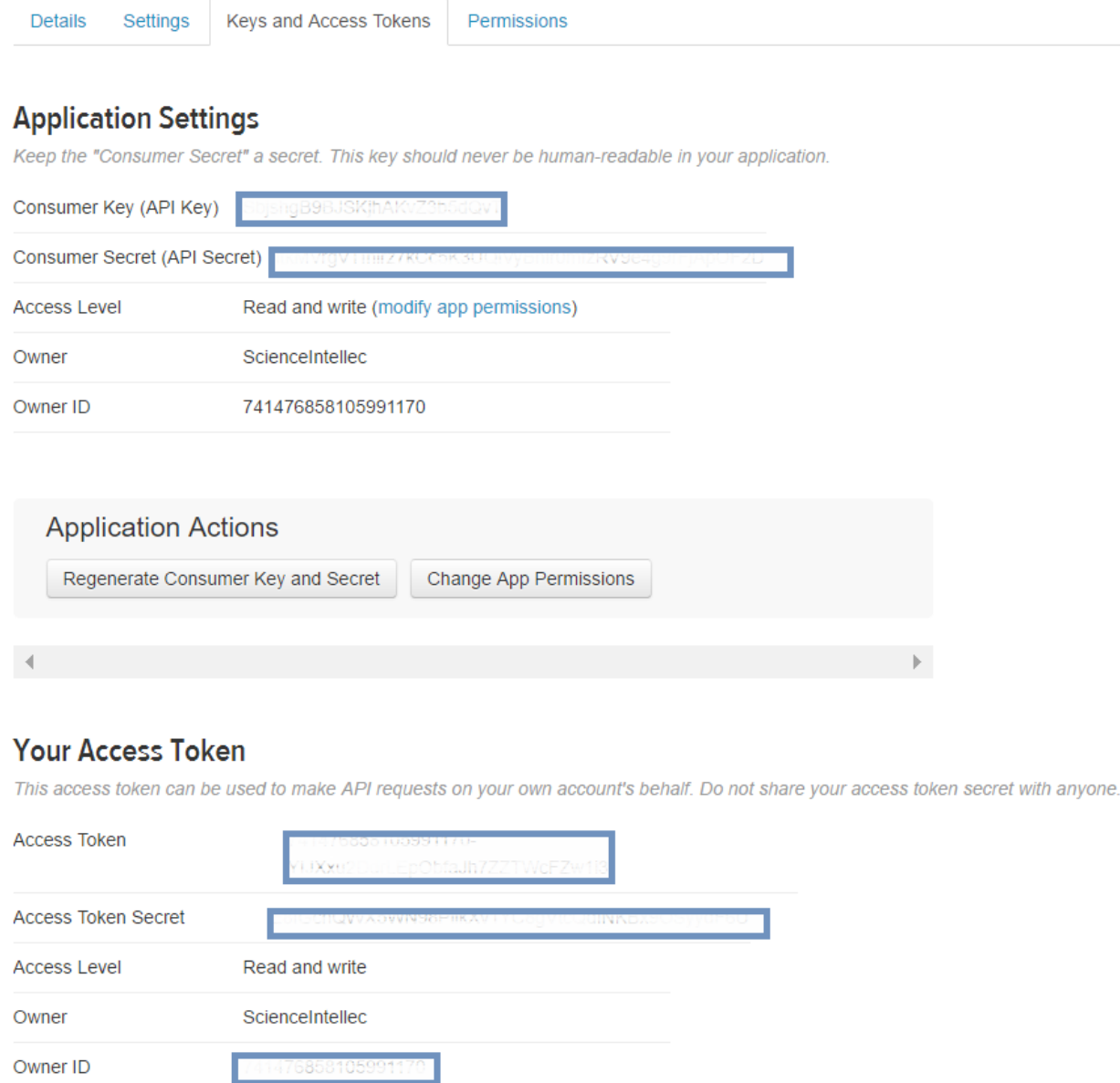

Figure 5-3 Access Tokens for the Twitter application

\subsection{PROGRAMMING THE TWITTER BOT}

For programming the Twitter bot, Python Scripts have been used. Python is a high-level, interpreted and dynamic programming language. Tweepy module of python has been used in coding the bot. Tweepy is a user friendly and easy library, which can be used to access the Twitter API. Figure 5-4 shows how a Twitter bot is used to update status and tweet to a user. 


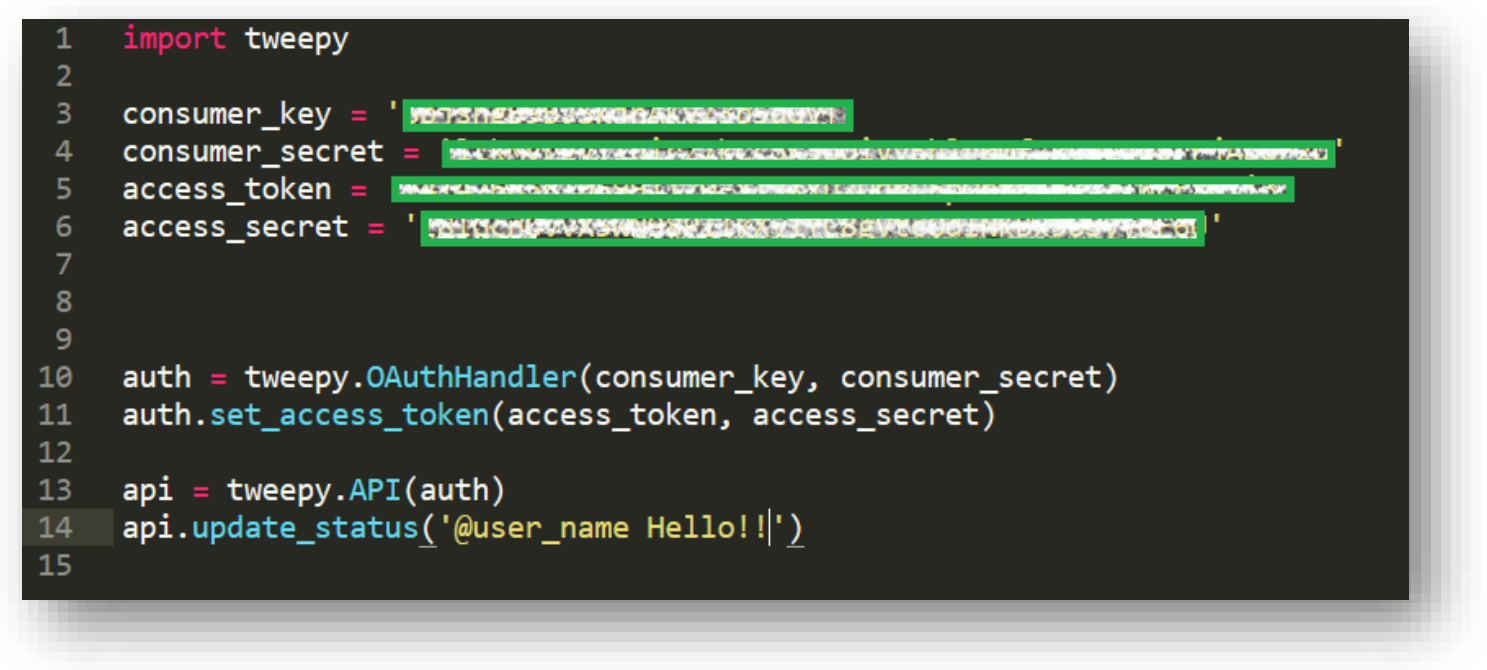

Figure 5-4 Tweet using Twitter bot

Firstly, the module Tweepy is imported. Then the consumer key, consumer secret, access key and access token that are acquired from the Twitter application (on the developer website) are updated in the code.

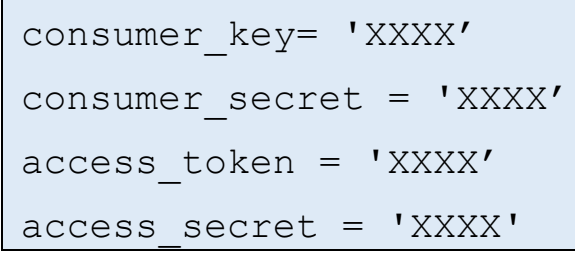

The access tokens are then used for OAuth to get authorized connection to the Twitter API.

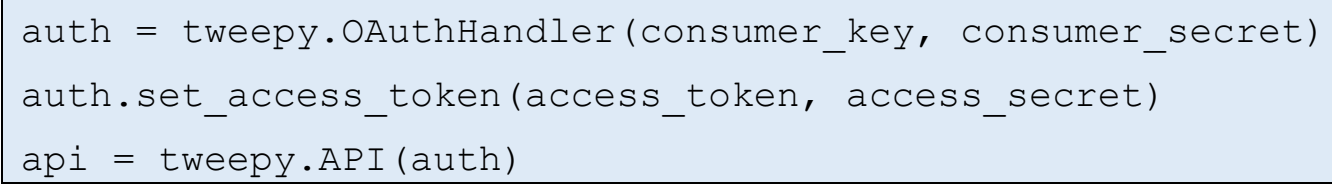

Using api.update_status (' @user_name Hello! !'), the status of the bot can be updated. By adding @user_name in the status message text, the bot can be used to tweet to other user accounts.

\subsection{SENDING TWEETS TO SCHOLARS \& SCIENCE FANS}

The Twitter bot code that is mentioned in the previous section is extended to tweet to Scholars \& science fans. The code in written in such a way that the bot takes usernames of the scholars \& science fans obtained in Study I. Figure 5-5 shows the Twitter bot is used to tweet to the list of scientists in the csv file. 


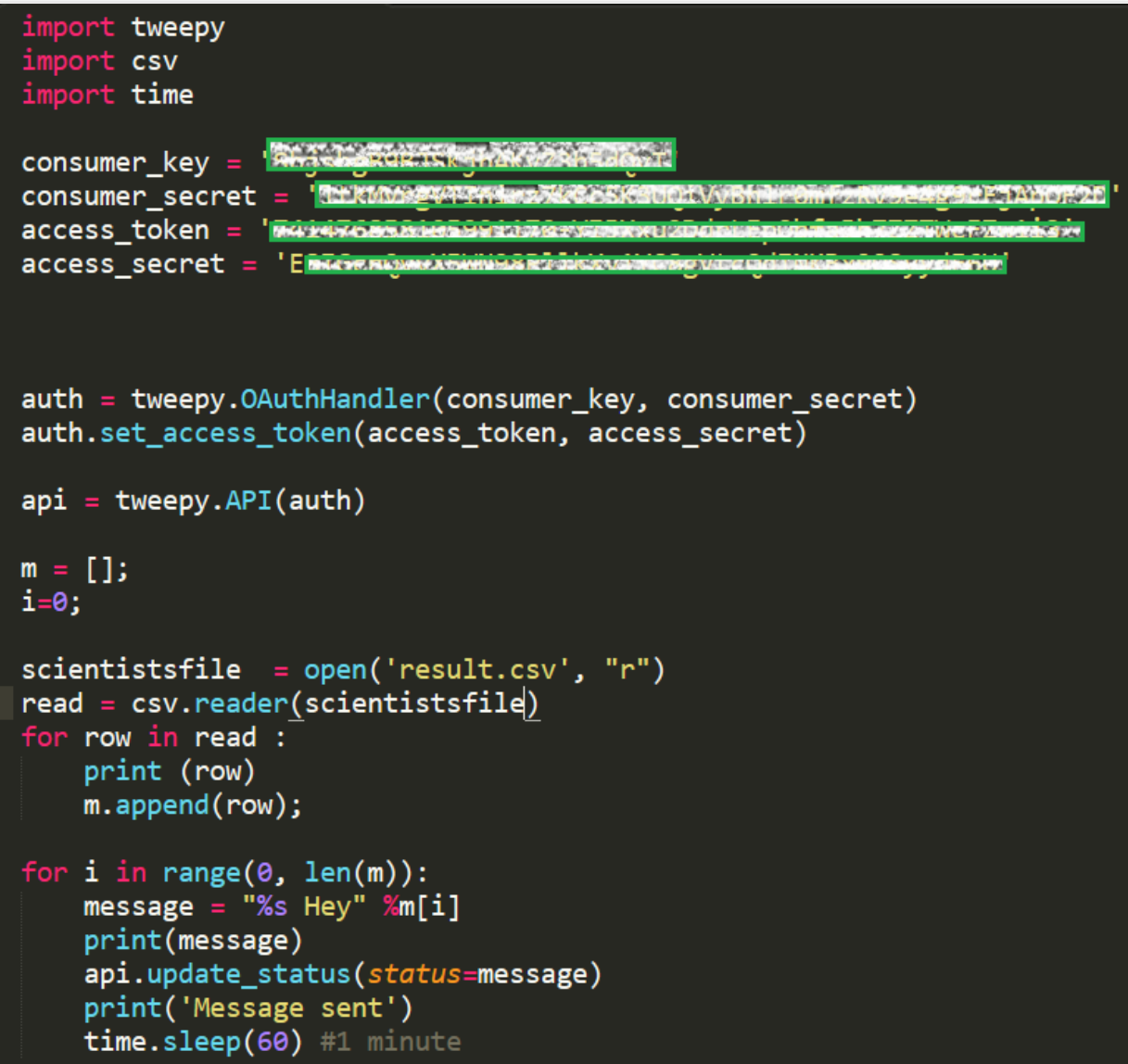

Figure 5-5 Tweeting to Scientists using Twitter bot

An array is used to store the usernames of scholars and science fans obtained from the csv file. The code below code shows how the csv file is read and each scholar username is added to the array.

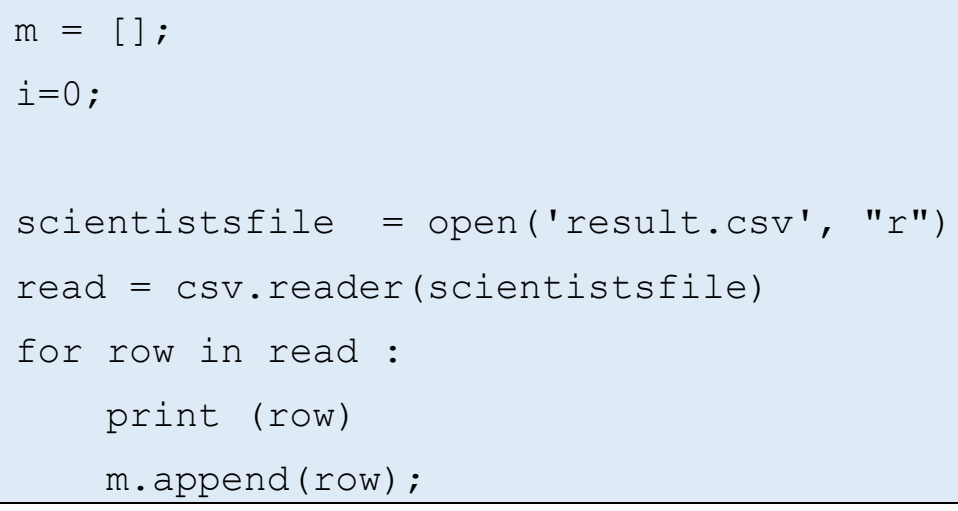


The bot tweets to one username with a customized message requesting to send a short summary of a research paper. The tweet is changed every 10 tweets. The bot waits for one minute after sending out one tweet. This is used by setting a timer of 60 seconds after each time the tweet is sent out.

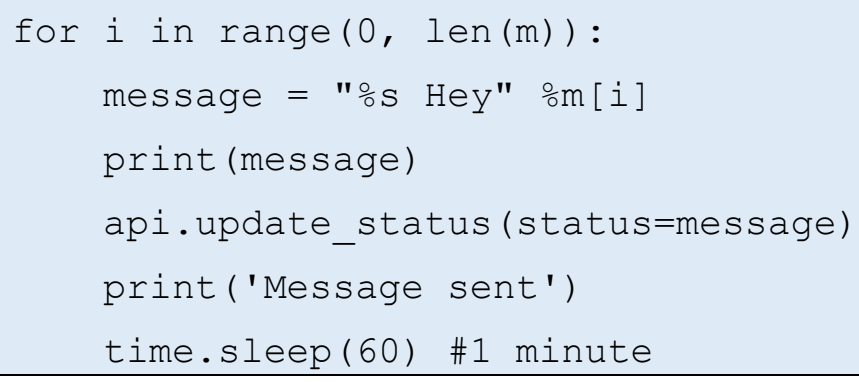

\subsection{COLLECTING NOVICE USERNAMES}

Once the short summaries are collected, the bot is used to collect the usernames of Twitter users who recently tweeted about the corresponding field. This is done by searching for the keyword or hashtag which contains the topic or field name for which the short summary is collected. The Figure 5-6 shows how the Twitter bot is used to collect the usernames of novices into a csv file.

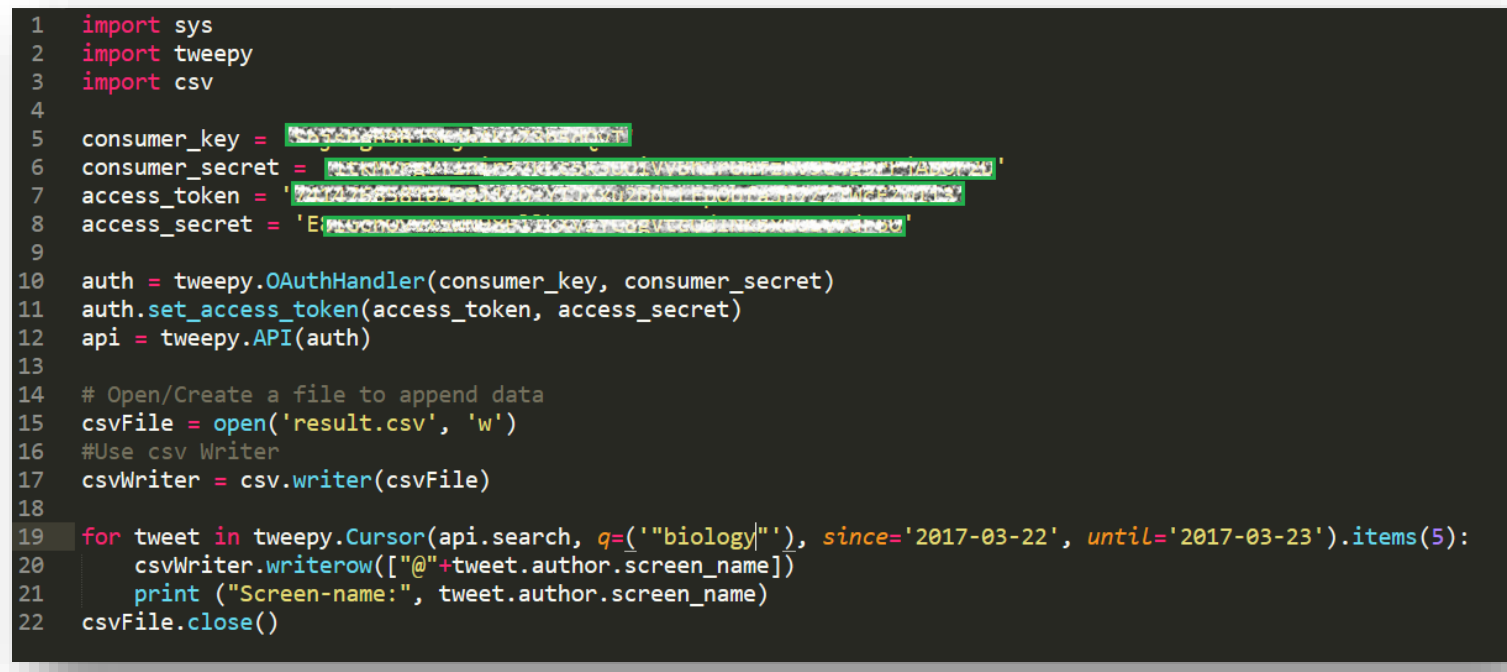

Figure 5-6 Collect novice usernames using Twitter bot

A csv file is created and saved with a desired name. Then tweets are searched that have the specified keyword that is required (field name or topic name) which have been tweeted in the desired timeframe (most recent). Number of usernames collected can be controlled by mentioning the number of items to be 
searched. After the tweets are searched, the tweet attribute author screen name is collected into the csv file created.

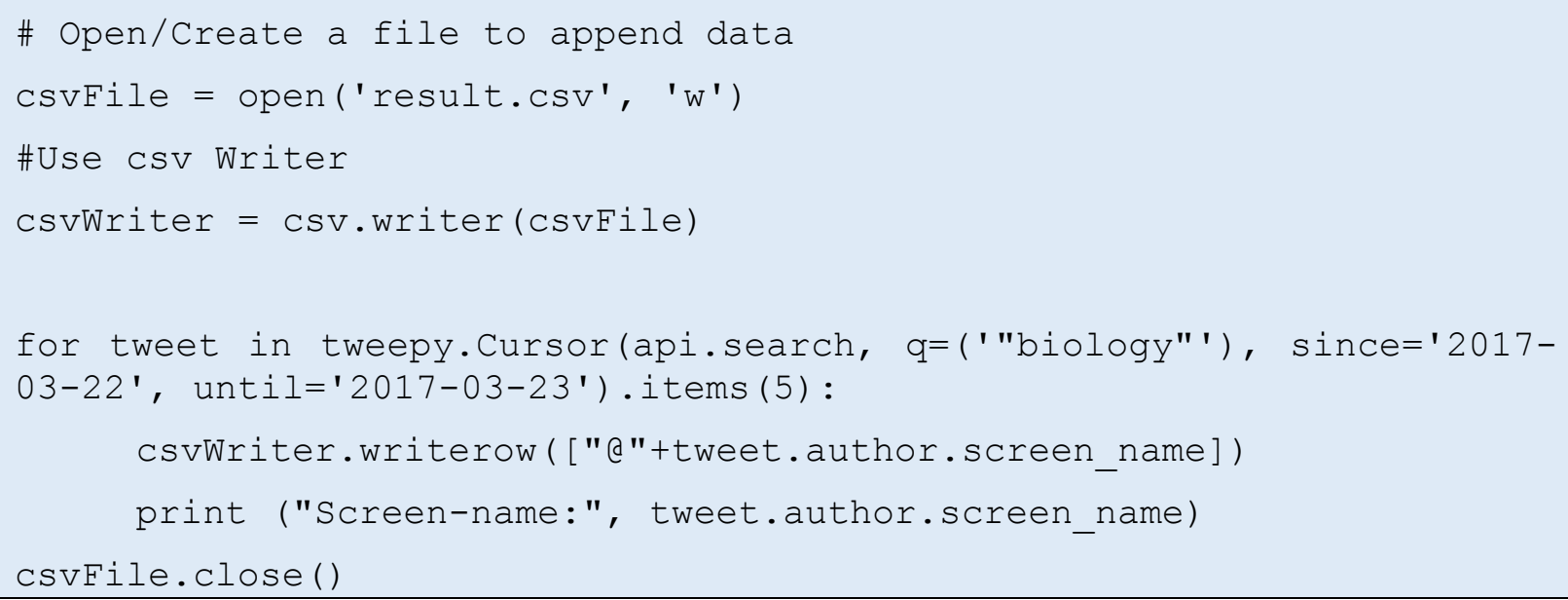

Once the novice usernames are collected into csv file, the novices are sent tweets with the short summary and request to like and retweet. 


\section{RESULTS}

\subsection{SCHOLARS \& SCIENCE FANS RESPONSES TO THE BOT AND OTHER STATISTICS.}

Using the Twitter bot (@ScienceIntellec) created in the implementation section, 53 scholars \& science fans were sent tweets requesting short description of their favorite research articles illustrated in Figure 6-1.

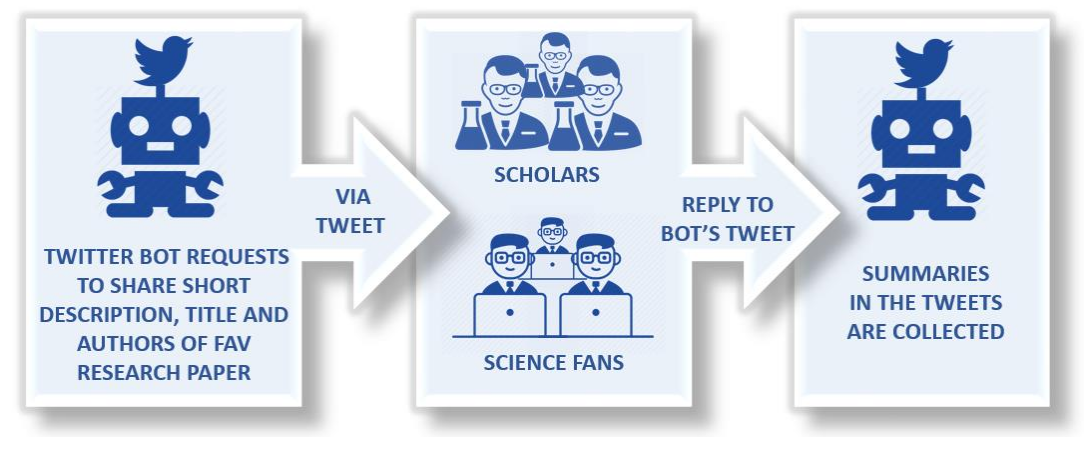

Figure 6-1 Figure illustrating the system implemented on Twitter

Different tweets were used to create the tweets. The messages used to tweet are:

- Contribute by sharing the gist of a research paper, see image for more scholar @user_name

- Hey scholar @user_name can you share a short summary of your favorite research paper?

- Scholar @ user_name Please share one line describing your favorite research paper.

Based on the Study II, there is a more chance of receiving responses when the tweet is sent along with an attached image describing the aim of the bot and how exactly the scholar can contribute. Hence Figure 6-2 was used to share along with the tweet.

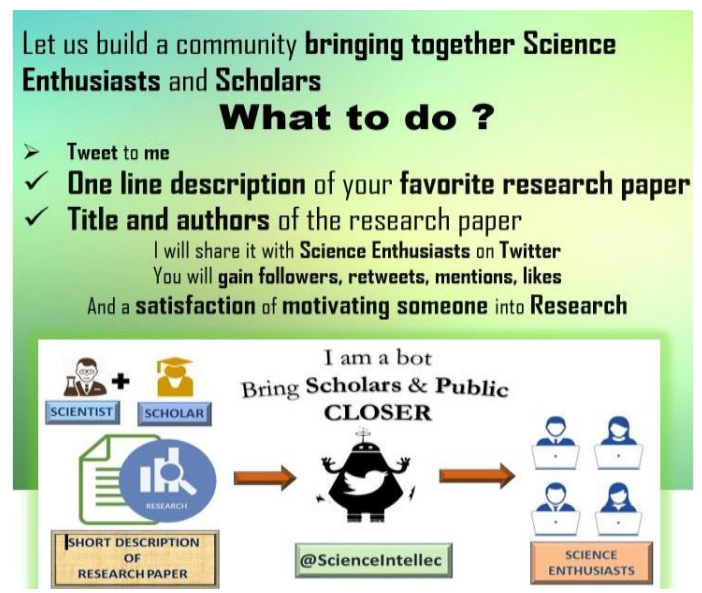

Figure 6-2 Image used to tweet to Scholars \& Science fans 
The bot received several responses. One of them is shown below in Figure 6-3 Response of a Scholar to the Twitter bot

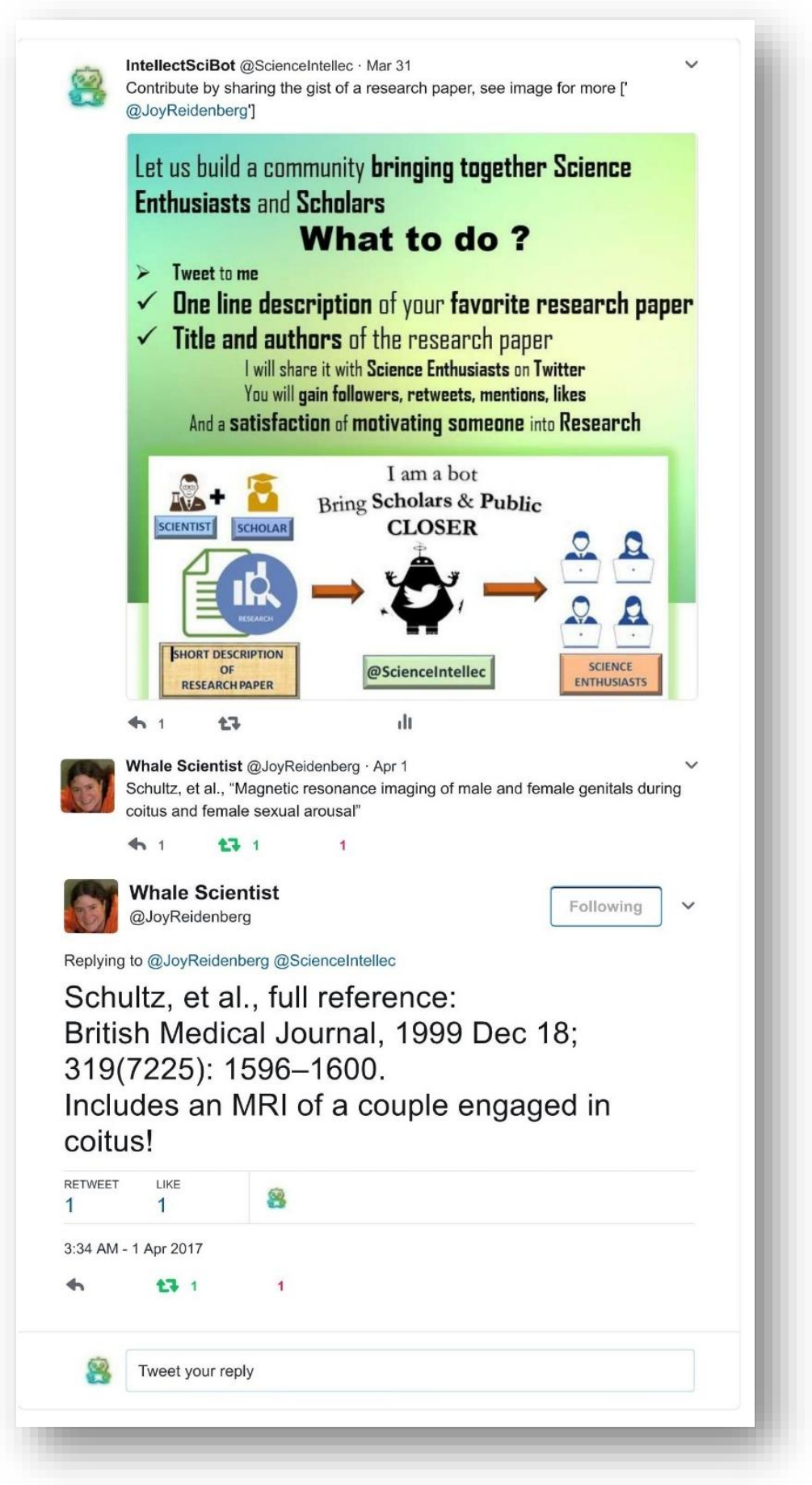

Figure 6-3 Response of a Scholar to the Twitter bot

Figure 6-4 shows the Twitter bot profile after implementing the system. 


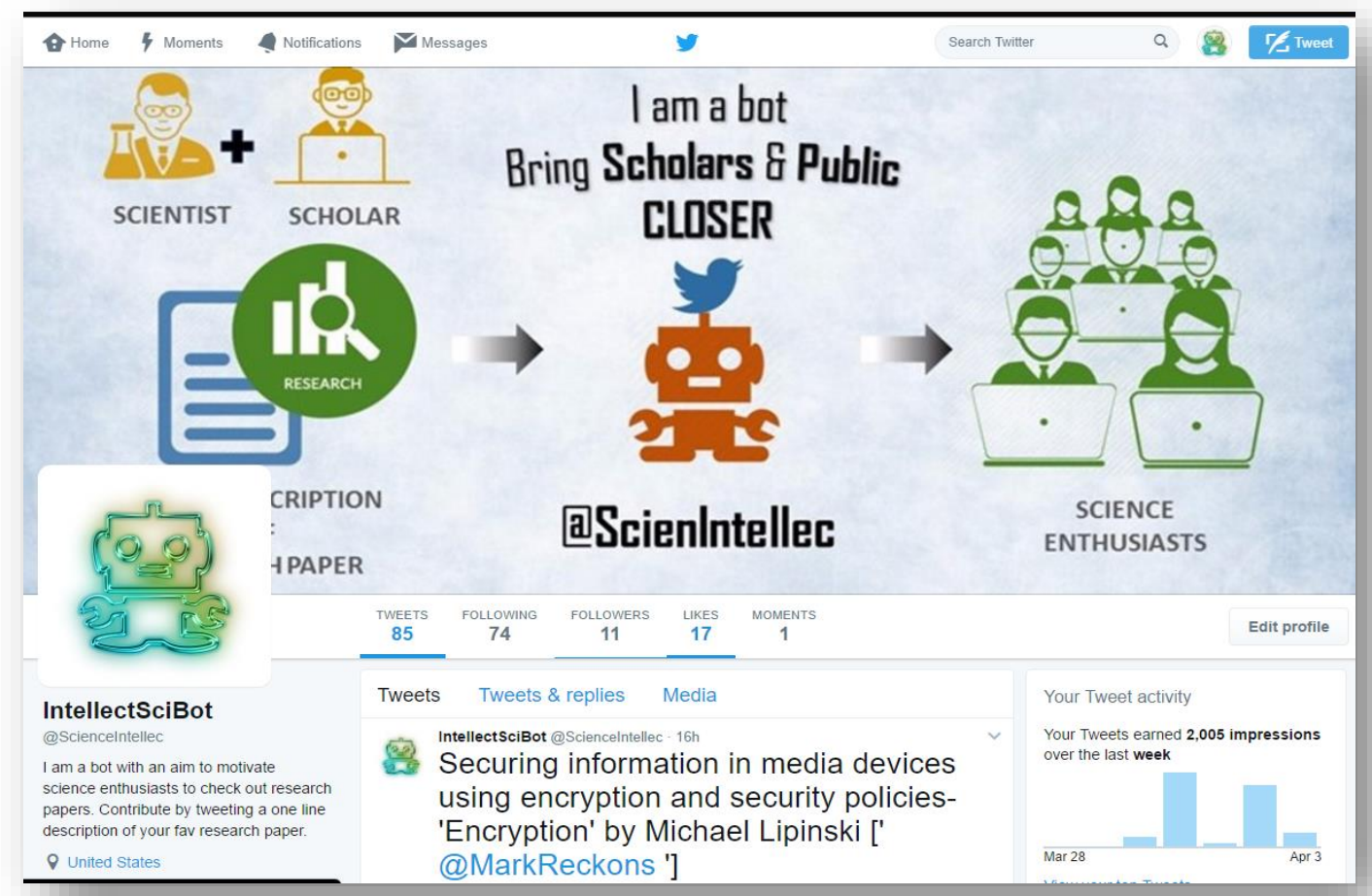

Figure 6-4 Twitter Bot profile after implementing the system

As a result, the bot received responses shown in Figure 6-5 below.

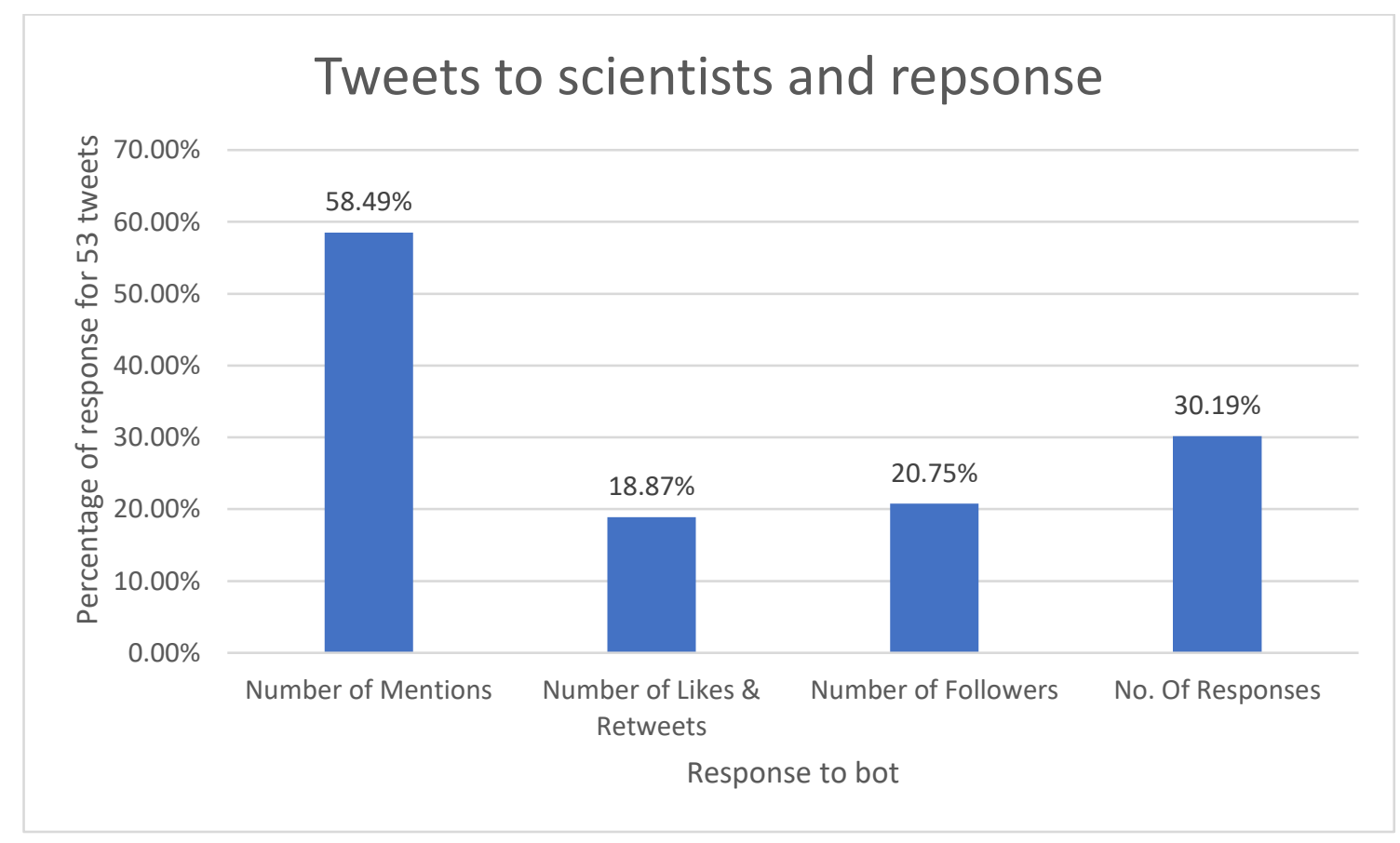

Figure 6-5 Tweets to scientists and response to bot 
It can be seen from Figure 6-5, that after implementing the system, the number mentions increased from $3.81 \%$ from study II to $58.49 \%$. There has also been a significant increase in the percentage of number of likes, retweets and followers. A total of $30.19 \%$ responses were received from the scholars \& science fans in the form of short summaries for their favorite research papers. These responses were then stores in an excel sheet.

\subsection{STUDY - RESPONSE OF NOVICES TO THE SYSTEM}

The aim of this study is to find out how novices react to the system. The objective of this system is to simulate the system to novices and document how they react to the system. For this study, 43 novices who are undergraduate (freshmen and sophomore) were considered. Each novice was shown a long research article and a short tweet size description of the given article. The Figure 6-6.

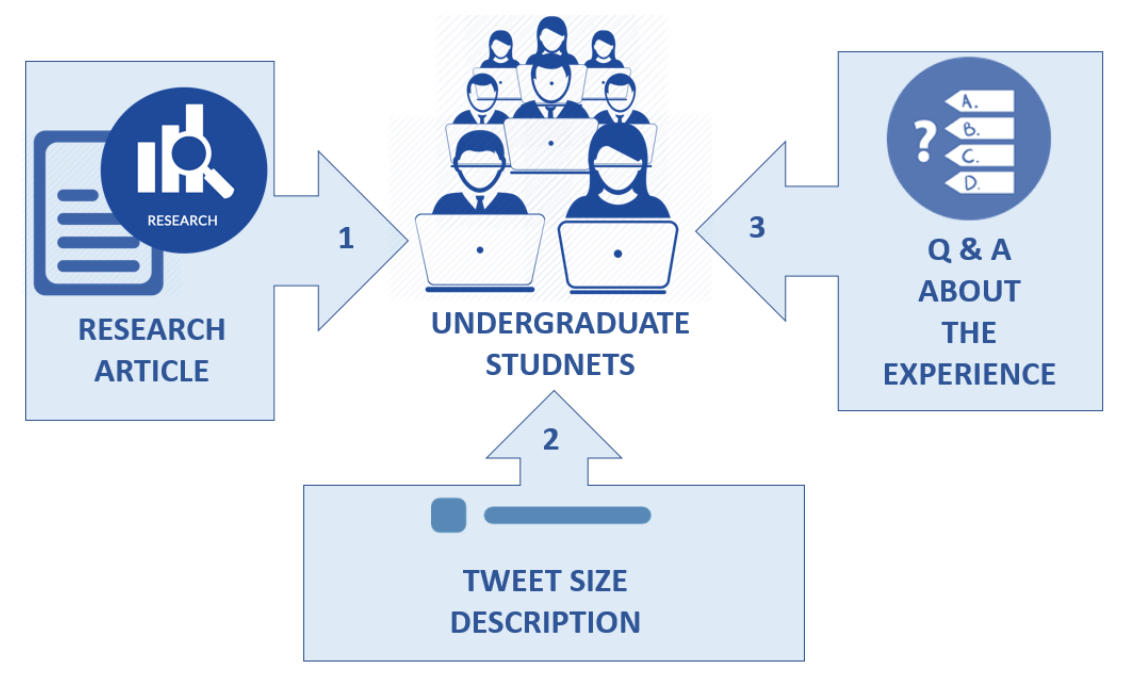

Figure 6-6 Figure illustrating simulation of system to novices and collection on responses

Each novice was asked five questions to better understand how exactly they reacted to the given system. The questions and the responses are given below.

The test topic used for this study was an article related to 'Application Programming Interface' (API). The novices were first asked the question given below.

Question 1: Do you know what 'Application Programming Interface' (API) is?

The responses given to this question are shown in Figure 6-7

It can be seen from Figure 6-7, that $6.98 \%$ novices knew what API was very clearly. $4.65 \%$ novices seem to have a good amount of understanding about the topic. But, $72.09 \%$ of the novices didn't really know what it meant. 


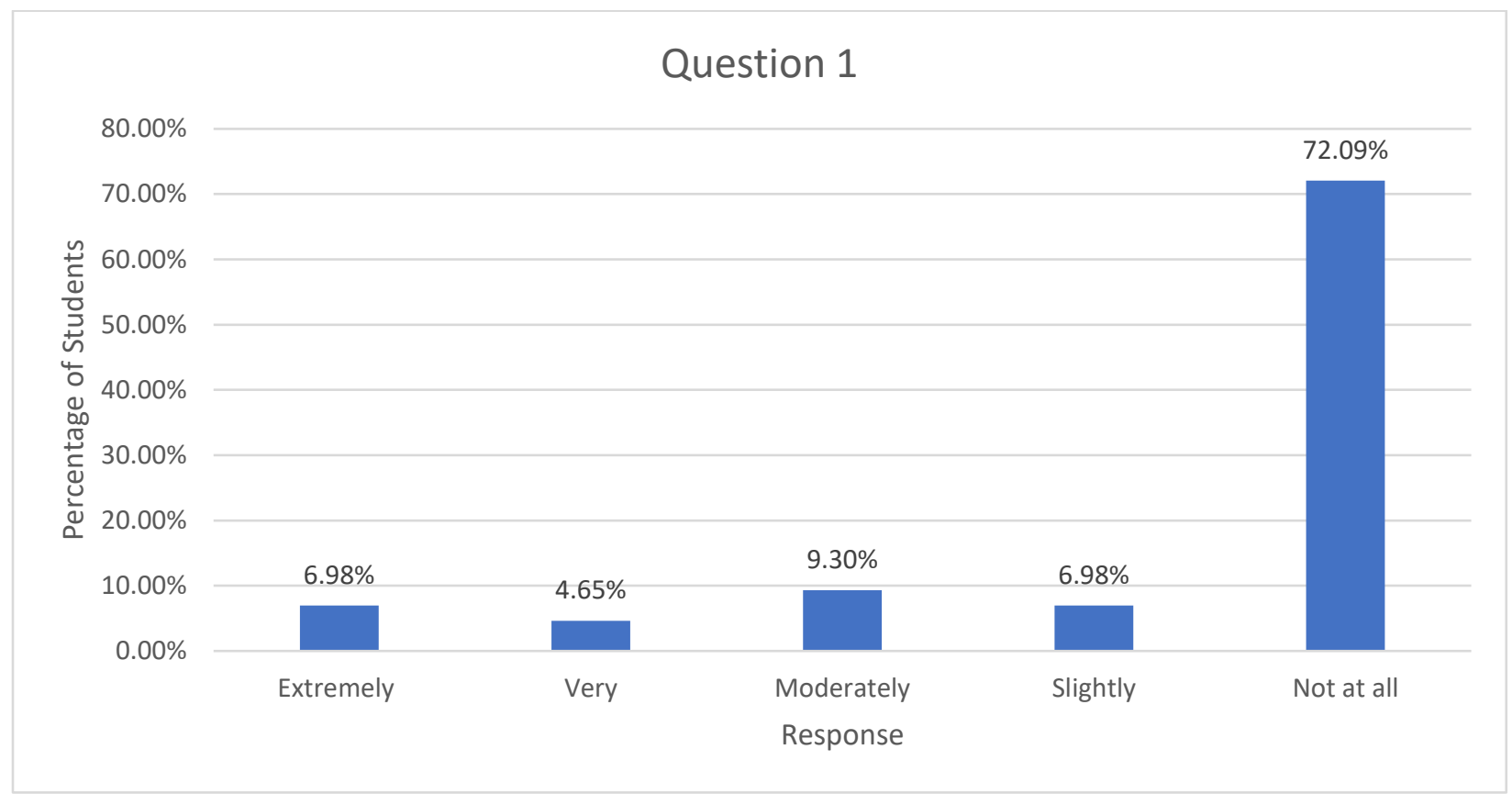

Figure 6-7 Response to Question 1

After asking about the knowledge of the test topic, the novices were asked if they want to read a research article about the test topic to learn more about it. The question and responses are shown below in Figure 6-8.

Question 2: Do you want to check out this research article about API?

It can be seen that, almost $7 \%$ of the novices have shown great interest in checking out the article. $4.65 \%$ of them were interested and $18.6 \%$ of them were moderately interested in checking out the article. However, $58.14 \%$ of them were not at all interested in checking out the article.

Next, the novices were presented with a research article about 'Application Programming Interface'. The novices were then asked the next question which is given below. The responses are shown in Figure 6-9. 


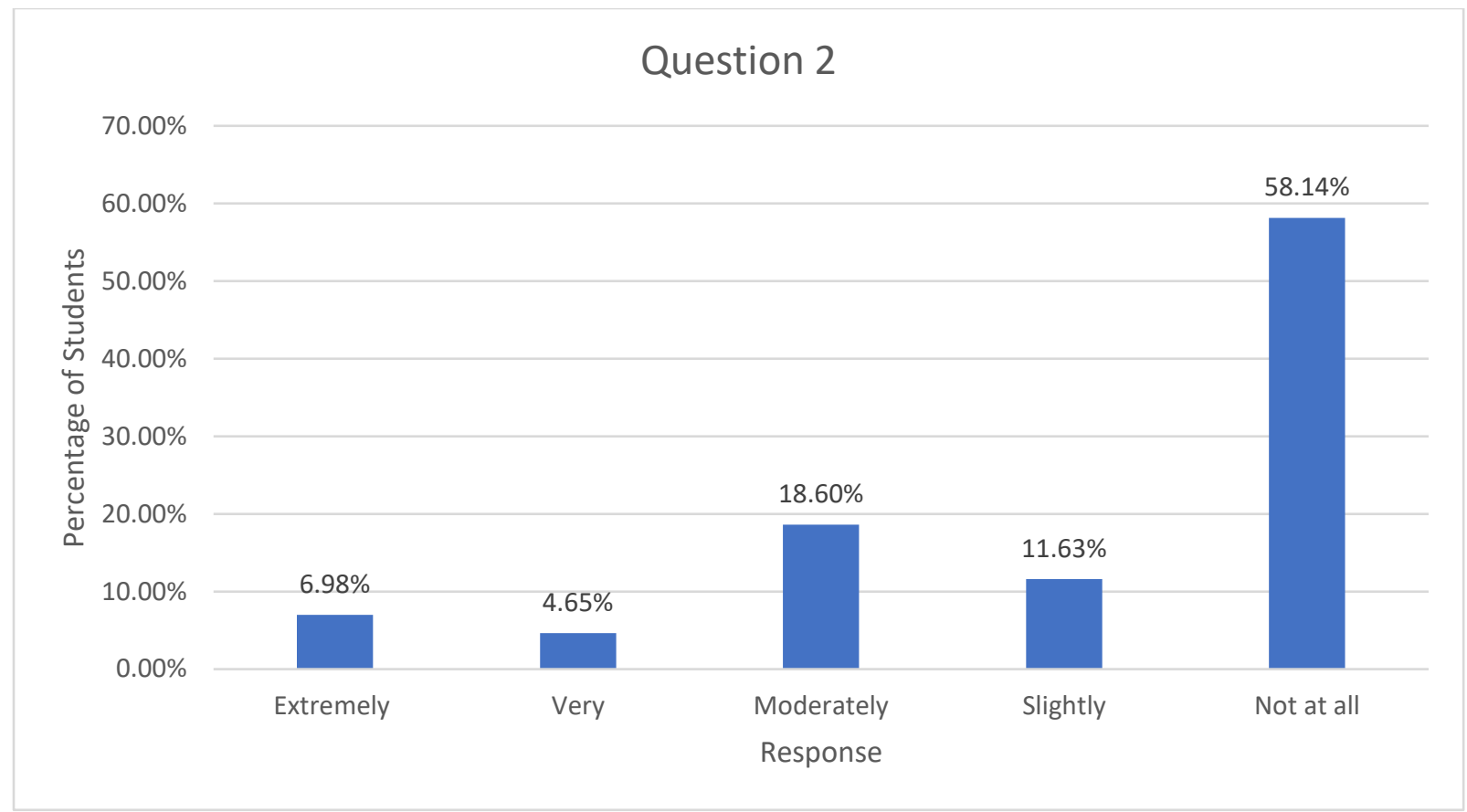

Figure 6-8 Responses to Question 2

Question 3: Did you read the research article given above?

It can be seen that number of people who read the article is $25.58 \%$. It can be seen that people who were interested and moderately interested, checked out the article.

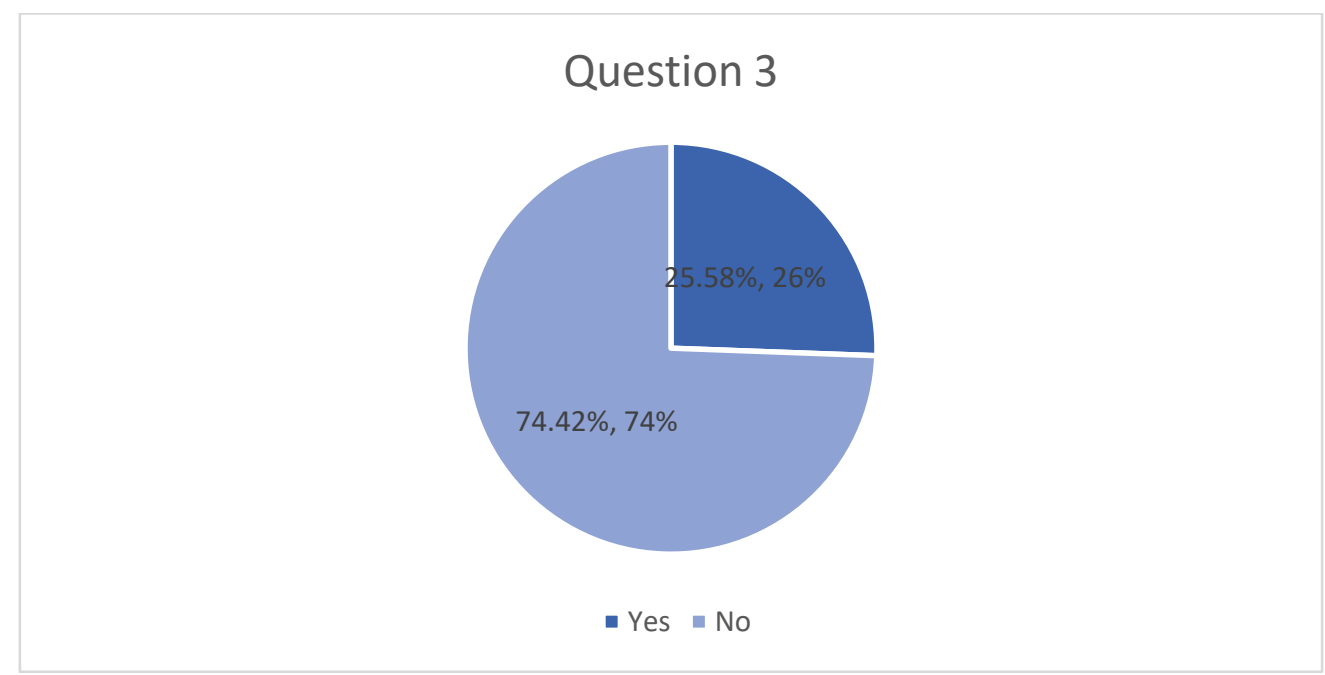

Figure 6-9 Responses to Question 3

The novices were then presented with a short tweet size description of what API is -API is a set of tools that can be used to build an app (application software) like Twitter, Facebook etc. 
The novices were then asked if the short description motivate them to check out the article. The question and responses (Figure 6-10) are shown below.

Question 4: API is a set of tools that can be used to build an app (application software) like Twitter, Facebook etc. Now that you know what it is, are you motivated to check out the article?

It can be seen from Figure 6-10, that as a result of the short tweet style description of the test topic, there has been an increase in the interest of novices to check out the research article. The percentage of novices extremely interested in checking out the article increases form $6.98 \%$ (before showing the short tweet size description) to $20.93 \%$ (after showing the short tweet size description). Similarly, percentage of novices greatly very interested increased from $4.65 \%$ to $9.3 \%$. The percentage of novices moderately interested also increased from $18.6 \%$ to $32.56 \%$. At the same time, there has been a reduce in the percentage of novices not at all interested. Thus, the short tweet size description of the topic managed to increase the motivation of novices to check out the research article that they were initially reluctant to skim through.

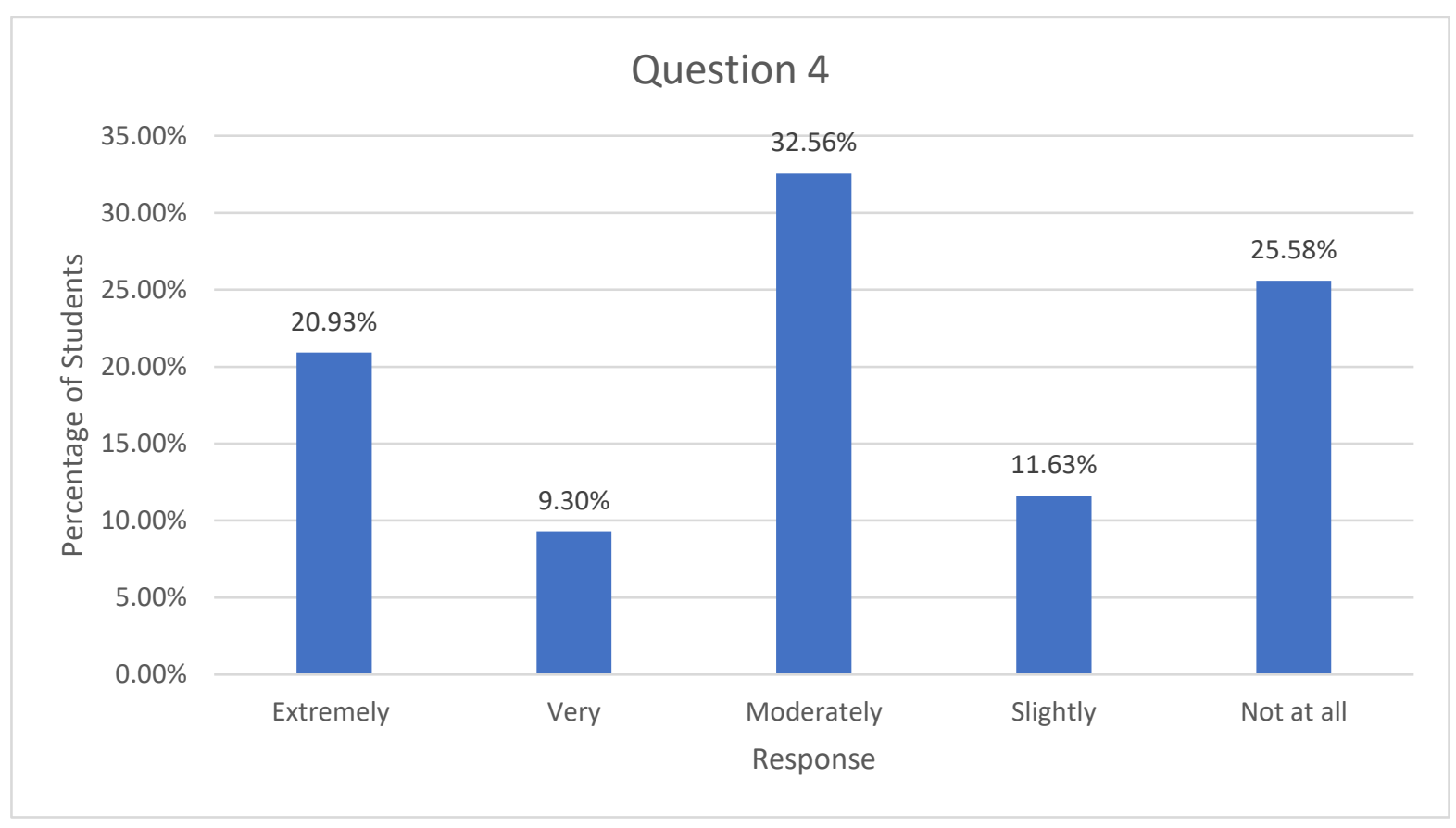

Figure 6-10 Responses to Question 4

To confirm the findings from the responses of the previous questions, the novices were asked directly if the short summary help to motivate them to check out the research article. The question and the responses (Figure 6-11) are shown below.

Question 5: Did the short summary given in the previous question motivate you to check out the research paper? 
It can be seen from Figure 6-11, that $18.6 \%$ of novices think that the short summary extremely motivated them to go back and refer to the research paper, $11.63 \%$ of novices think that it motivated them very much and $27.91 \%$ say that it moderately motivated them. It can be observed that there is a significant increase in novices' interest to check out the research article, from directly exposing them to the research article to after giving a short description of what the research article is talking about.

The conclusions are made based on the responses of the novices to this particular field. The results may vary based on the target set of novices and the field. The conclusion is a generalized understanding of how novices respond to any generic topic.

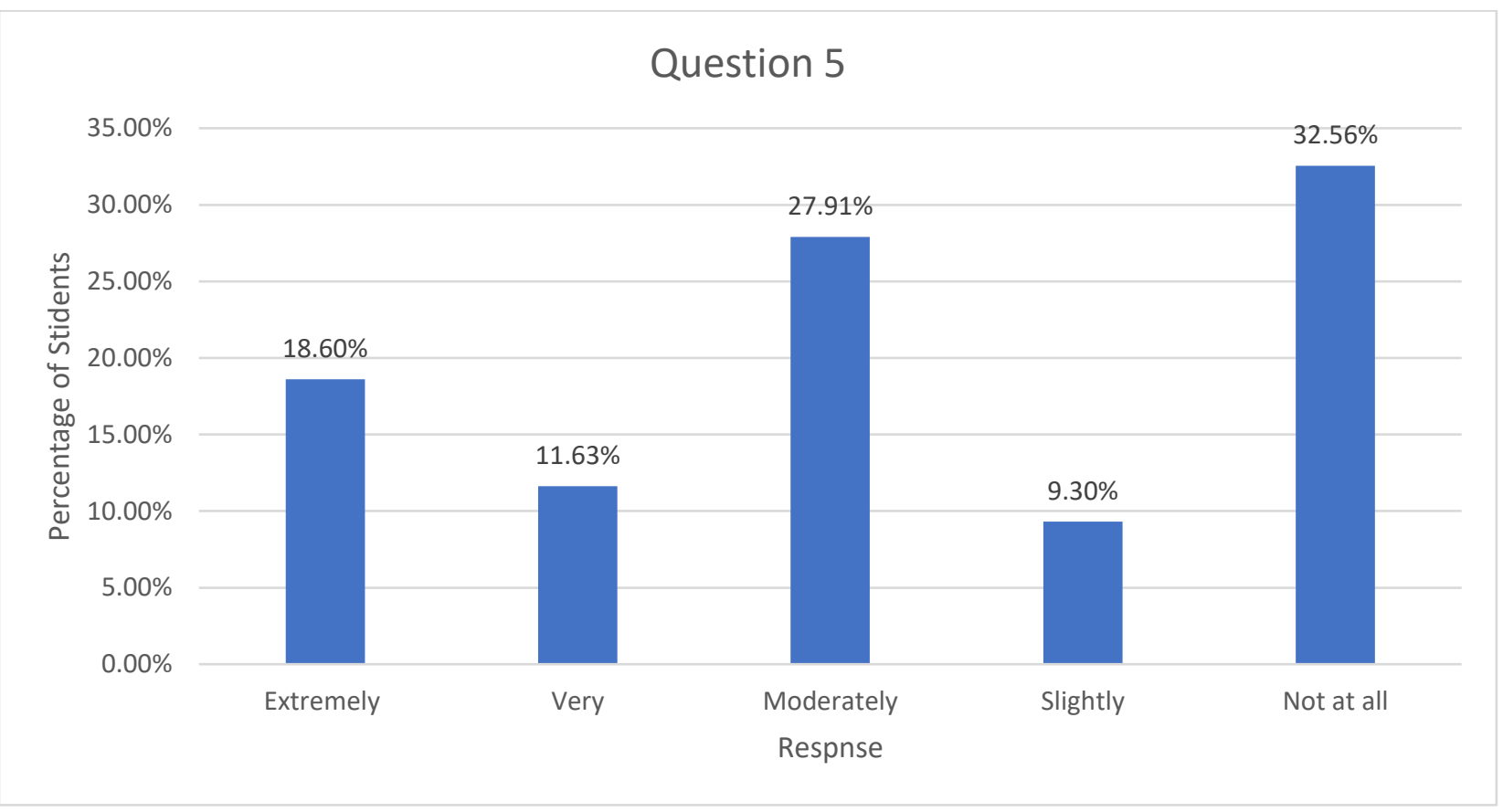

Figure 6-11 Responses to Question 5 


\section{DISCUSSION}

\subsection{MOTIVATING SCHOLARS \& SCIENCE FANS TO SHARE KNOWLEDGE}

The proposed system demonstrates how we can use Twitter bots to help aid scholars and science fans to share their knowledge with novices and motivate them to check out research articles. Initially, when the scholars and science fans were approached to share their knowledge by giving a short summary of their favorite work or research article, very less number of responses were received. Thus, different strategies were used like changing up the tweet posted by the bot, attaching an image to the tweet that would catch the attention of the scholar or science fan. This approach managed to get better number of responses, but not a good number. There was also a negative feedback to the bot requests in the form replies to the tweet.

As a result of this, another study was conducted whose aim was to know how scholars \& science fans would react to a bot, and also their perspective about the idea of contributing by sharing to the general public. The results of this study were interesting. Scholars \& science fans didn't show much interest in replying to the bot or sharing knowledge on social media for various reasons. Some of those reasons were found to be as lack of time, interest and motivation to share and maintain social media presence. However, some of the scholars \& science fans were willing to give time to share their knowledge with the public if they could see a quantifiable positive feedback and if they were convinced that their contribution is valuable, relevant and would motivate general public.

When the final system when implemented on Twitter, the bot tweeted to scholars \& science fans with different tweets requesting to contribute by sharing a short description/summary of their favorite research article. Along with the tweet, an image was attached which showed the brief process flow of the system and a short motivational description of what the scholars $\&$ science fans are expected to do. As a result, there was an increase in the amount of responses received. In the process, the bot account also received increased number of mentions, likes, retweets and followers.

\subsection{MOTIVATING NOVICES TO CHECK OUT RESEARCH ARTICLES}

To understand more about how the novices are currently using social media for learning, studies have been conducted on graduate and undergraduate student of WVU. It was found that around $50 \%$ of the graduate students used social media for learning. They expressed their interest in looking up on the internet for their 
favorite fields of research and are also interested to check out online sources to keep themselves updated with new and upcoming research work. The studies conducted on undergraduate students showed that most of them agree that they are not updating themselves with the upcoming research work. Even though they have the university databases accessible to them, they still do not get motivated to check out the research articles because they find the research articles are written with term and language that is too complex for them. However, most of them admitted that if they can check out a short summary/description of a research article in simple terms, ten they would be motivated to check out the research paper.

The final system was implemented by simulating the system to a group of novices. The novices were asked several questions and their responses were collected in Likert scale to better understand their reaction to the system. The final study showed a close relationship between the initial study results. When the group of novices were given a research article and asked to read it, very less (7\%) of them showed interest to check out the research paper. However, when they were given a short tweet sized description of what the research article is talking about then the novices interest to check out the research article increasing significantly. 


\section{CONCLUSION}

The aim of this problem report was to propose a system that can bridge the gap between the elite scientific community (scholars\& science fans) and the novices (novices) who are interested in science and technology by motivating them to explore the research areas and research papers in their field of interest. The system managed to increase the number of responses received from scholars \& science fans when compared to the study (study II) done before the system was implemented. The given system after it was implemented received a small response considering the timeframe and the number of people we could target. The received response however, is positive. Most people who saw the short summaries were interested and motivated to have a look at the research paper that the summary belonged to. This serves the purpose of our system whose goal is to intrigue people interested in science to get exposed to the wonderful research that has been done and is being done in their favorite research area and thus attempting to bridge the gap between them and scientists.

\section{LIMITATIONS AND FUTURE WORK}

Our proposed system does seem to attempt to bridge the gap between the general public and the scientific community by motivating scholars \& science fans to share knowledge and motivating novices to check out research articles. However, certain limitations can be considered for our system. The most important one is that the system is being implemented only on Twitter meaning that only active users of Twitter are being targeted and measured by the scope of this system. The next limitation is that people who are really interested in science and want to learn and explore more may not have access to social media or they may not be interested, thus limiting the people who could be positively influenced in getting motivated towards science by this approach. Another limitation is the number of people we are able to target on Twitter using this approach, since not many are always active on Twitter, the chances of getting back responses are not equal to the requests sent by bot.

To overcome these limitations, future work can be done by implementing this system on other social media platforms and target it to a larger audience to see how significantly it is impacting the people and observe if it is moving closer to bridge the gap between scholars \& science fans and novices. Another direction that this system can be implemented and tested out is to create an app or website that can be represented by the Twitter bot account. The app or website can be created such that the short summaries/descriptions (collected from scholars \& science fans) are all documented and categorized based on the related field following by a 
link to the original article (using google scholar). This could allow novices to check out short summaries from any field they desire and in turn check out the research articles.

\section{REFERENCES}

[1] Bell, Philip, National Research Council (U.S.), Committee on Learning Science in Informal Environments. Learning science in informal environments : people, places, and pursuits.

[2] R. Calder, Science and the Common Man. France: UNESCO, 1965.

[3] Welborn, Victoria; Kanar, Bryn. Building websites for science literacy. Issues in Science \& Technology Librarianship (25), 2000.

[4] Pool, R. Science literacy: The enemy is us. Science 251(4991), pp. 266-67. 1991.

[5] Levy, R. Literary Guide. 1955.

[6] Lerner, RM; Fisher, CB; Weinberg, RA. Toward a science for and of the people: Promoting civil society through the application of developmental science. Child Dev. 71(1), 2000.

[7] Castronovo, C; Huang, L. "Social Media in an Alternative Marketing Communication Model. ," 2012.

[8]Taylor A, W.E.G, Using Twitter for student learning \& connecting with scientists. Am.Biol.Teach.American Biology Teacher 78(7), pp. 599-602. 2016.

[9] Spires, Hiller A.; Lee, John K.; Turner, Kimberly A.; Johnson, Janet. Having our say: Middle grade student perspectives on school, technologies, and academic engagement. Journal of Research on Technology in Education 40(4), pp. 497-515. 2008.

[10] Twitter, "About Twitter" [Online]. Available: https://about.Twitter.com/company. [Accessed 2017].

[11] DeSanctis; Gerardine; Fayard; Anne-Laure; Roach, Michael; Lu,Jiang,. Learning in online forums. European Management Journal 21(5), pp. 565-577. 2003.

[12] Tozman, R. (). Learning on demand: how the evolution of the Web is shaping the future of learning.

[13] Thomas, M.J.W. Learning within incoherent structures: The space of online discussion forums. $J$. Comput. Assisted Learn. 18(3), pp. 351-366. 2002. . DOI: 10.1046/j.0266-4909.2002.03800.x.

[14] Rudich, J. Internet learning. Link - Up 15(5), pp. 23. 1998.

[15] Perry; Edward, H.; Pilati; Michelle L. Online learning. TL New Directions for Teaching and Learning 2011(128), pp. 95-104. 2011.

[16] Medford A.R.L. Online learning. Quality in Primary Care 12(1), pp. 87-89. 2004. 
[17] Ebizmba, " Top 15 Most Popular Science Websites" [Online]. Available: http://www.ebizmba.com/articles/science-websites. [Accessed 2017].

[18] Dreamgrow, " Top 15 Most Popular Social Networking Sites" [Online]. Available: https://www.dreamgrow.com/top-15-most-popular-social-networking-sites/. [Accessed 2017].

[19] Wikipedia, "Internet Forum" [Online]. Available: https://en.wikipedia.org/wiki/Internet_forum [Accessed 2017].

[20] Rowntree, D. Teaching and learning online: A correspondence education for the 21st century? British Journal of Educational Technology 26(3), pp. 205-215. 1995. . DOI: 10.1111/j.1467-8535.1995.tb00342.x.

[21] Bates, T. Technology, Open Learning, and Distance Education 1995.

[22] Twitter, "The Twitter Glossary" [Online]. Available: https://support.Twitter.com/articles/166337 [Accessed 2017].

[23] Twitter, " Getting Started with Twitter" [Online]. Available: https://support.Twitter.com/articles/215585 [Accessed 2017].

[24] Gragg P, S.C.L. Twitter. Law Libr.J.Law Library Journal 102(2), pp. 325-330. 2010.

[25] Grosseck, G.;Holotescu, C "Can We Use Twitter for Educational Activities?" 2008.

[26] Galagan, P. Twitter as a learning tool. really. $T+D$ 63(3), pp. 28-29,31. 2009.

[27] Trinkle, C. Twitter as a professional learning community. School Library Media Activities Monthly. 26(4), pp. 22-23. 2009.

[28] Ebner; Martin; Lienhardt; Conrad; Rohs; Matthias; Meyer, Iris. Microblogs in higher education - A chance to facilitate informal and process-oriented learning? CAE Computers \& Education 55(1), pp. 92100. 2010.

[29] Bik HM, G.M. An introduction to social media for scientists. PLoS Biology 11(4), 2013.

[30] Orduna-Malea, E.; Martin-Martin, A.; Delgado-Lopez-Cozar, E. The next bibliometrics: ALMetrics (author level metrics) and the multiple faces of author impact. Prof.Inf.Profesional De La Informacion 25(3), pp. 485-496. 2016.

[31] Andrews; Elisabeth; Weaver; Alex; Hanley; Daniel; Shamatha; Jeffrey; Melton; Ginger. Scientists and public outreach: Participation, motivations, and impediments. Journal of Geoscience Education / 53(3), pp. 281. 2005. 
[32] Akmon, D. 6th Annual Conference on 2011 iConference: Inspiration, Integrity, and Intrepidity, iConference 2011,. Moving beyond sharing vs. withholding to understand how scientists share data through large-scale, open access databases. ACM Int.Conf.Proc.Ser.ACM International Conference Proceeding Series pp. 634-635. 2011.

[33] Campbell, EG; Clarridge, BR; Gokhale, M; Birenbaum, L; Hilgartner, S; Holtzman, NA; Blumenthal, D. Data withholding in academic genetics: Evidence from a national survey. Jama 287(4), pp. 23-30. 2002.

[34] Searchexchange, "Application program interface (API)" [Online]. Available:

http://searchexchange.techtarget.com/definition/application-program-interface [Accessed 2017].

[35] Wikipedia, "Application program interface" [Online]. Available:

https://en.wikipedia.org/wiki/Application_programming_interface [Accessed 2017].

[36] Twitter, " OAuth" [Online]. Available: https://dev.Twitter.com/oauth [Accessed 2017].

[37] Techtarget, " OAuth" [Online]. Available

http://searchmicroservices.techtarget.com/definition/OAuth [Accessed 2017].

[38] Wikipedia, "Application program interface" [Online]. Available:

https://en.wikipedia.org/wiki/OAuth [Accessed 2017].

[39] Wikipedia, " Representational state transfer" [Online]. Available:

https://en.wikipedia.org/wiki/Representational_state_transfer [Accessed 2017].

[40] Twitter, " REST APIs" [Online]. Available: https://dev.Twitter.com/rest/public [Accessed 2017].

[41] Iag.me, "How to Register a Twitter App in 8 Easy Steps" [Online]. Available

https://iag.me/socialmedia/how-to-create-a-Twitter-app-in-8-easy-steps/ [Accessed 2017]. 


\section{APPENDIX A}

\subsection{Python code for sending tweets}

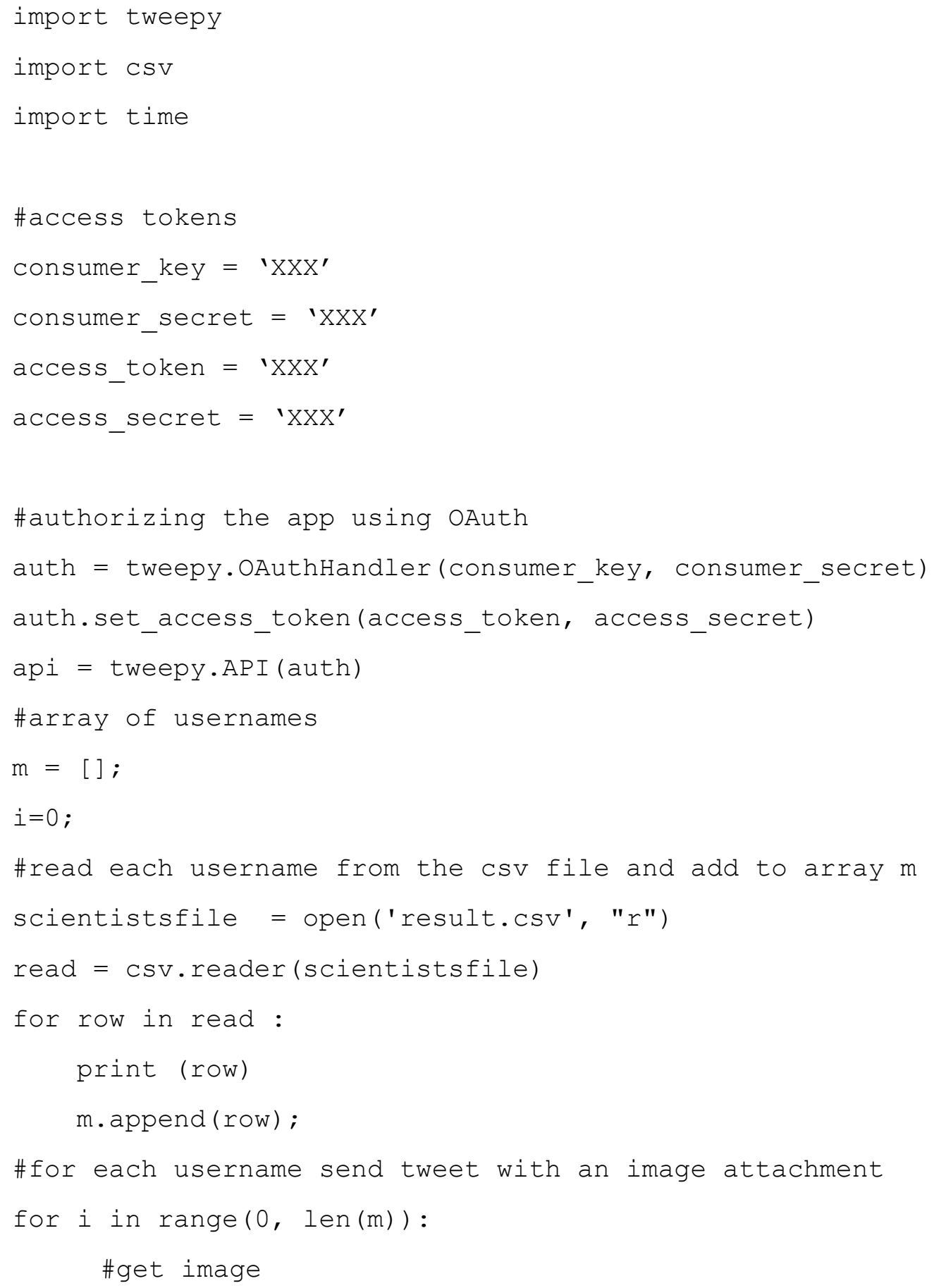




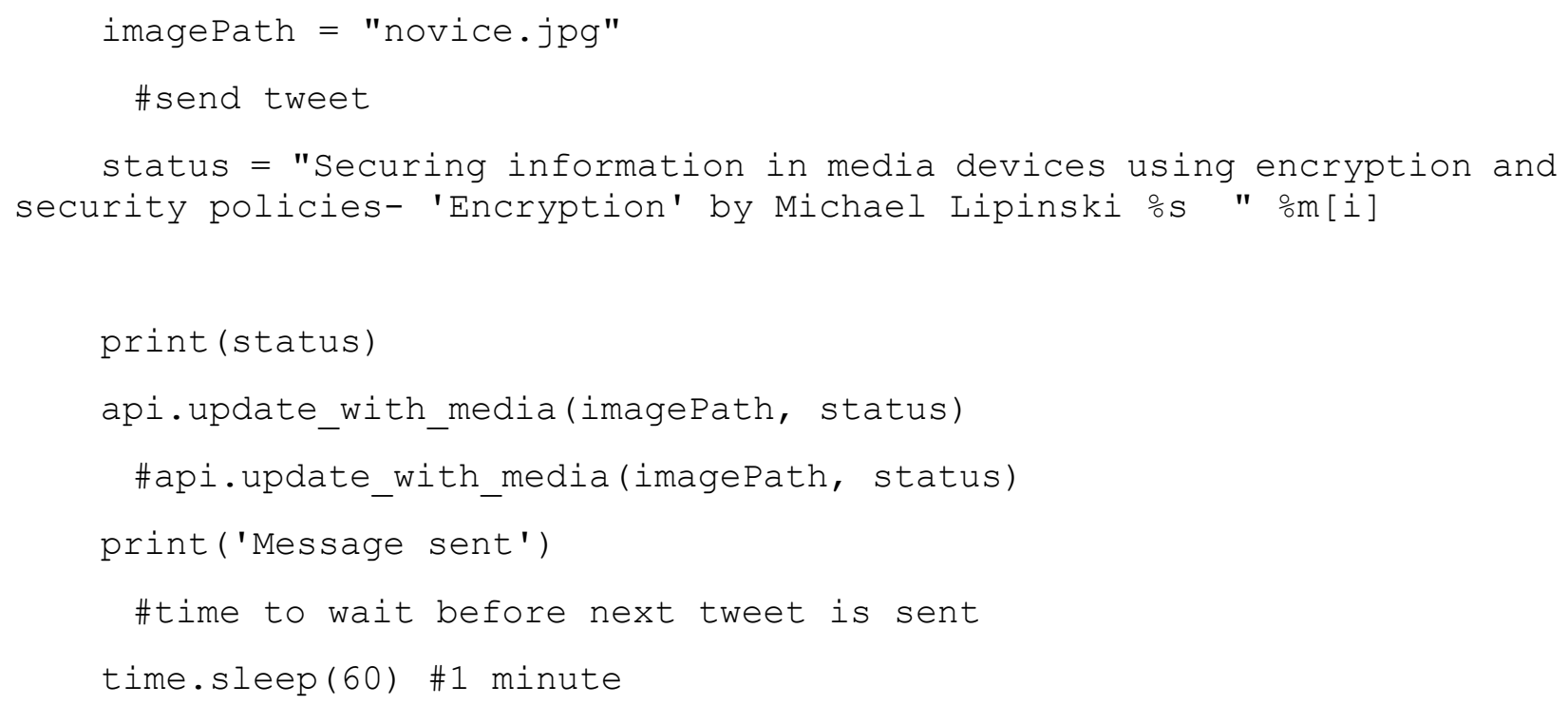

\subsection{Python code for collecting usernames into csv file based on required keyword}

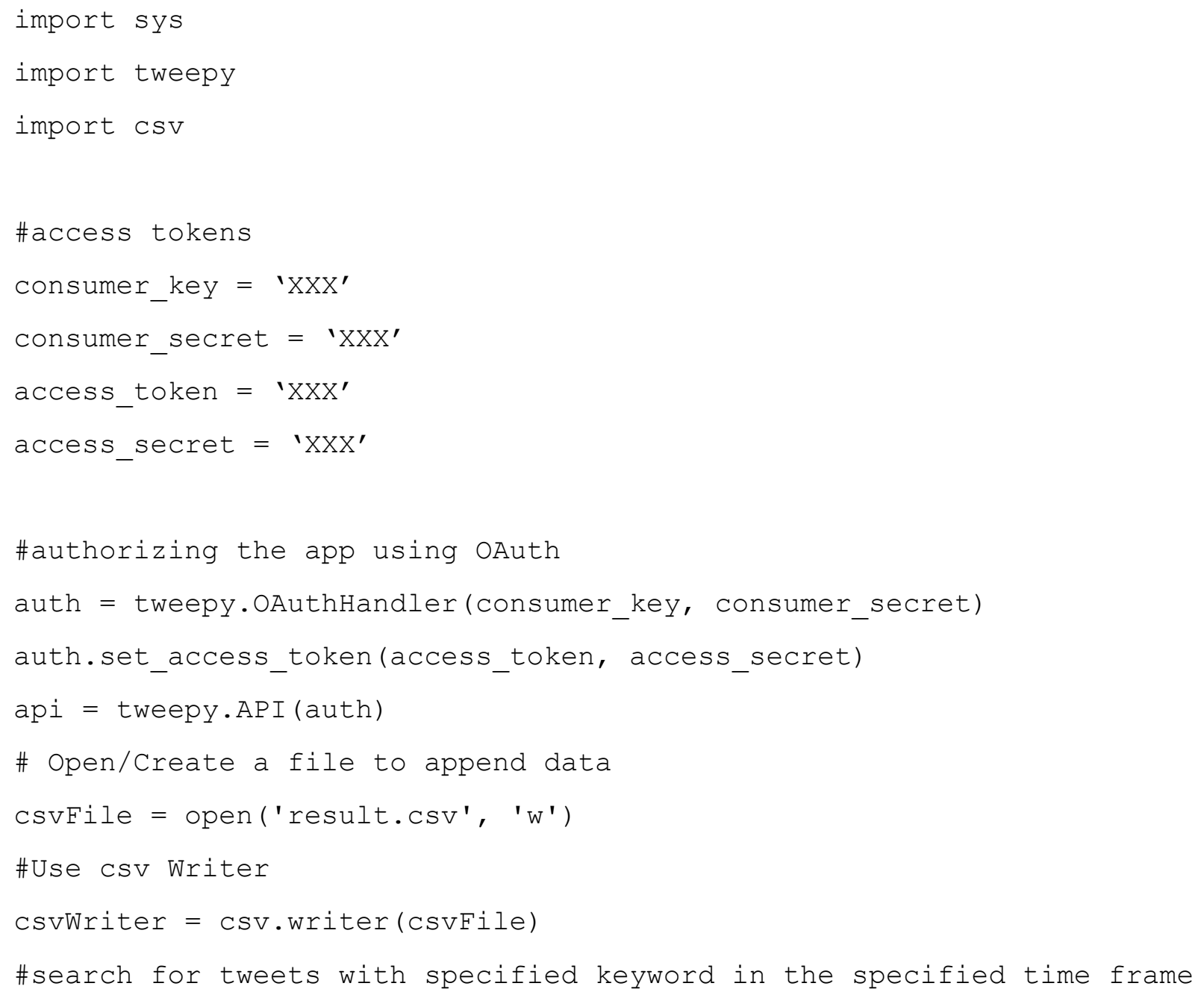


for tweet in tweepy.Cursor(api.search, $q=($ 'biology"'), since='2017-03-

22', until='2017-03-23').items (5):

\#write the username to the csv file

csvWriter.writerow (["@ "+tweet.author.screen_name])

print ("Screen-name:", tweet.author.screen_name)

, csvFile.close() 